University of Missouri, St. Louis

IRL@ UMSL

7-17-2014

\title{
The Relation of Anxiety, Depression, and Stress to Binge Eating Behavior
}

Diane L. Rosenbaum

University of Missouri-St. Louis

Follow this and additional works at: https://irl.umsl.edu/dissertation

Part of the Psychology Commons

\section{Recommended Citation}

Rosenbaum, Diane L., "The Relation of Anxiety, Depression, and Stress to Binge Eating Behavior" (2014). Dissertations. 235.

https://irl.umsl.edu/dissertation/235

This Dissertation is brought to you for free and open access by the UMSL Graduate Works at IRL @ UMSL. It has been accepted for inclusion in Dissertations by an authorized administrator of IRL @ UMSL. For more information, please contact marvinh@umsl.edu. 
The Relation of Anxiety, Depression, and Stress to Binge Eating Behavior

\author{
Diane L. Rosenbaum, M.A.
}

M.A., Clinical Psychology, University of Missouri - St. Louis, 2010

B.A., Psychology, Boston University, 2005

A Dissertation Submitted to The Graduate School at the University of Missouri - St.

Louis in partial fulfillment of the requirements for the degree

Doctor of Philosophy in Psychology with an emphasis in Behavioral Medicine

July 19, 2013

Advisory Committee Kamila White, Ph.D.

Chairperson

Steven Bruce, Ph.D.

Zoë Peterson, Ph.D.

Susan Kashubeck-West, Ph.D.

Copyright, Diane L. Rosenbaum, 2013 
Table of Contents

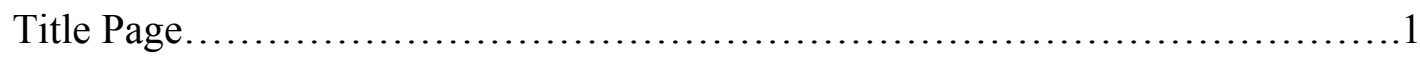

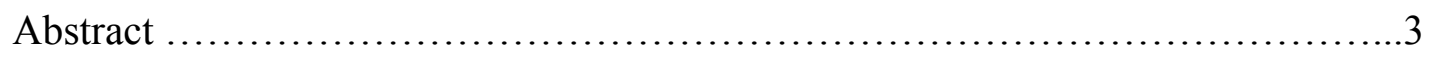

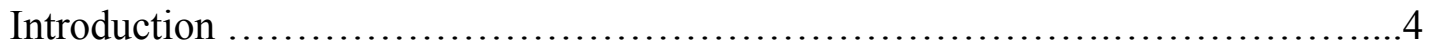

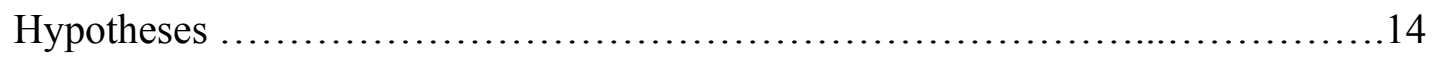

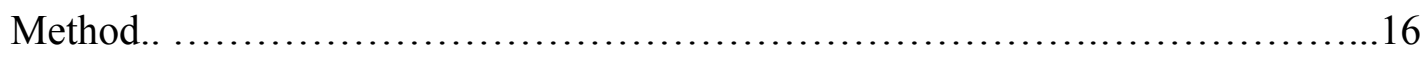

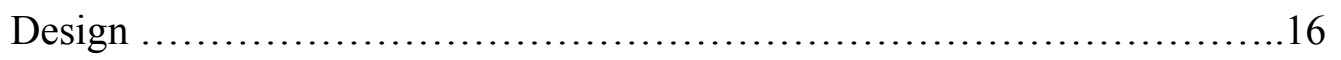

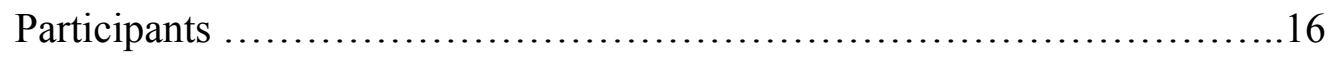

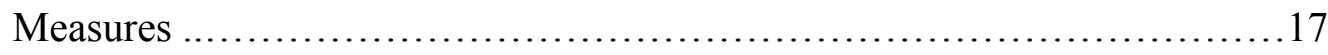

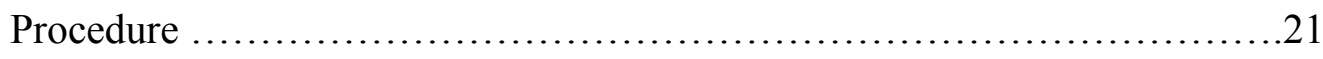

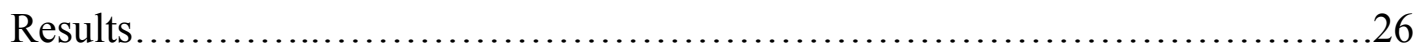

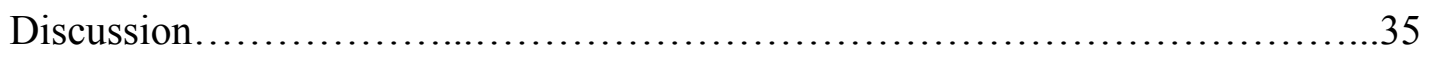

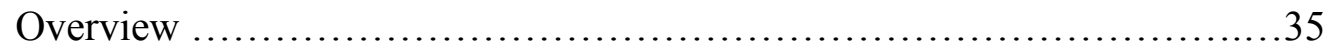

Limitations............................................................. 44

Future Research and Clinical Implications...............................45

Conclusion............................................................... 49

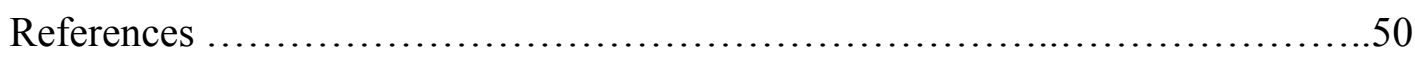

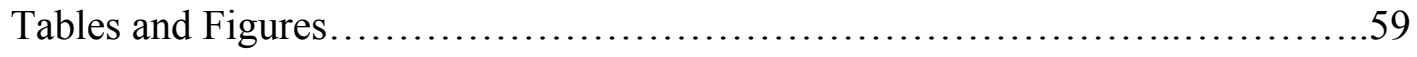

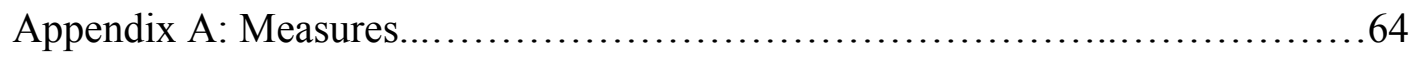




\begin{abstract}
Binge eating is an impairing and prevalent problem. Theories of binge eating suggest negative affect is of primary importance in the development and maintenance of binge eating behavior. To date, investigations of binge eating have often examined depression, however relatively little is known about other psychological factors. The current study aimed to extend the literature by examining several psychological factors in relation to binge eating behavior. Specifically, the relation between binge eating behavior and three psychological factors, depression, anxiety and stress, were examined. Data were collected via online surveys from a community sample of men and women of diverse backgrounds. The main study hypotheses were supported, indicating a unique relation between anxiety and binge eating, and between stress and binge eating, independent of the impact of depression. Additionally, secondary analyses supported the role of cognitive avoidance as a mediator in the relation of anxiety and binge eating. Hostility was also examined in relation to binge eating. The results of this study suggest a need for greater inclusivity (i.e., anxiety, stress) of dimensions of negative affect in examinations of binge eating. Further, focused attention regarding the role of anxiety may be important for future binge eating research.
\end{abstract}


The Relation of Anxiety, Depression, and Stress to Binge Eating Behavior

Binge eating is an impairing condition that is associated with psychological distress. Decreased quality of life, medical comorbidities, and psychological dysfunction are common among individuals with binge eating (Grucza, Przybeck, \& Cloninger, 2007; Guerdjikova, McElroy, Kotwal, \& Keck, 2007; Hudson, Hiripi, Pope Jr, \& Kessler, 2007; Javaras et al., 2008; Reichborn-Kjennerud, Bulik, Sullivan, Tambs, \& Harris, 2004). Binge eating is the most common type of disordered eating. Epidemiological research suggests binge eating disorder is approximately four to seven six times as prevalent as anorexia nervosa and approximately two to four times as prevalent as bulimia nervosa in the general population (Hudson et al., 2007). Moreover, community-based estimates suggest that binge eating can be a chronic problem; on average, individuals may experience binge eating for six to nine years (Hudson et al., 2007; Taylor, Caldwell, Baser, Faison, \& Jackson, 2007). Given the magnitude of this problem, it is important to identify factors that may impact the development and maintenance of binge eating.

\section{Definitions of binge eating}

Binge eating is a dimensional construct occurring across clinical and subclinical levels (Azarbad, Corsica, Hall, \& Hood, 2010; Grilo, 2002; Grucza et al., 2007; Spitzer et al., 1992). The DSM-5 defines clinically significant binge eating [i.e., Binge Eating Disorder (BED)] as eating a quantity of food that is definitely larger than average within a specific period of time. During this eating episode, the individual experiences a loss of control over eating and may experience negative emotions in relation to this episode, during or after its occurrence (American Psychiatric Assocation, 2013). Subclinical levels 
of binge eating are not formally defined by the DSM, however the study of subclinical symptomology may contribute to greater understanding of the syndrome overall. Subclinical binge eating may be defined as repeated episodes of DSM-defined binge eating (i.e., marked by time-limited overeating and loss of control) in the absence of compensatory behaviors but without a sufficient number of other criteria to meet the diagnostic threshold.

It is important to consider the utility of dimensional examinations of binge eating. A variety of factors may influence the severity of binge eating, however dichotomous definitions of "clinical" and "subclinical" do not adequately capture the variability with which these symptoms may be expressed. Similarly, given that the definition of "clinically significant" binge eating is subject to change upon revision of the DSM, dimensional examinations may be more applicable to the future literature. Research suggests that despite its categorization below the threshold of clinical significance, subclinical binge eating is associated with a host of impairments, including psychological dysfunction (Javaras et al., 2008; Reichborn-Kjennerud, Bulik, Sullivan, et al., 2004; Striegel-Moore, Wilfley, Pike, Dohm, \& Fairburn, 2000).

\section{Prevalence}

Binge eating is prevalent at clinical and subclinical levels. Estimates suggest current rates of BED are approximately $2 \%-6 \%$ in community samples (Grucza et al., 2007; Hudson et al., 2007). Subclinical prevalence estimates range from $2 \%-4 \%$ (Bruce \& Agras, 1992; Hudson et al., 2007). These prevalence rates are notably higher than those reported for other types of disordered eating, such as anorexia nervosa and bulimia nervosa (Hudson et al., 2007). 
Similarly, the heterogeneity of the population affected by binge eating is also noteworthy. Research indicates that across clinical and subclinical levels, binge eating is the most common form of eating disturbance among men (Hudson et al., 2007), with prevalence rates ranging from approximately $2 \%-32 \%$ (Hudson et al., 2007; KashubeckWest, Mintz, \& Weigold, 2005; Lewinsohn, Seeley, Moerk, \& Striegel-Moore, 2002). Binge eating is also a common occurrence among individuals from minority backgrounds (Azarbad et al., 2010; Marcus, Bromberger, Wei, Brown, \& Kravitz, 2007; Mazzeo, Saunders, \& Mitchell, 2005; Shaw, Ramirez, Trost, Randall, \& Stice, 2004). In fact, binge eating is the most common and persistent form of disordered eating among African-Americans (Taylor et al., 2007).

\section{Empirically Supported Theory}

Several theories have been proposed to understand binge eating. Negative affect is a common component across various models of binge eating (Fairburn, Cooper, \& Shafran, 2003; Heatherton \& Baumeister, 1991; Sherry \& Hall, 2009). In addition to their shared emphasis on the importance of negative affect, most models have posited that binge eating results from a combination of predisposed vulnerability factors and environmental triggers. Developed in a field replete with models for bulimia nervosa and anorexia nervosa, some binge eating models [e.g., (Sherry \& Hall, 2009)] include factors that are of debatable significance to binge eating, such as dietary restraint (Abbott et al., 1998; Binford, Mussell, Peterson, Crow, \& Mitchell, 2004; Spitzer et al., 1993). Theories that have centered on the relation between psychological factors, such as anxiety, depression, and stress, and their connection to binge eating, have received empirical support. One such example meriting discussion is cognitive avoidance theory. 
Cognitive avoidance theory proposes that binge eating serves as a method by which individuals limit negative thoughts. In turn, this limits or reduces negative emotions (Heatherton \& Baumeister, 1991). As such, binge eating has been suggested to function as an anxiety reduction strategy (Pallister \& Waller, 2008). Some have explained this process as an "escape from awareness," (Heatherton \& Baumeister, 1991) in which the salience of negative emotions is limited through cognitive narrowing. During a process of cognitive narrowing, the complexity of stimuli is minimized such that thoughts are ascribed a concrete quality; interaction with the environment occurs on a more basic level. Thoughts are limited to processing to the concrete experiences of binge eating (e.g., chewing) rather than more abstract concepts and beliefs (e.g., self-concept). As such, consequences of binge eating are not salient during the act itself and cognition is solely occupied by current behavior. By limiting the scope of awareness, individuals who engage in binge eating are able to blunt the negative impact that current circumstances may present to their present or future condition (Heatherton \& Baumeister, 1991).

Extrapolating from this theory, cognitive narrowing may serve to reduce the impact of negative thoughts about both the current stressor as well as the chosen method of self-soothing (i.e., binge eating). Alexithymia, which is characterized by an avoidant coping style, preference for concrete processing styles, and limited emotion-focused communication skills, has been linked to emotional eating among individuals with BED (Pinaquy, Chabrol, Simon, Louvet, \& Barbe, 2003). This suggests that when facing difficult emotional experiences and limited resources for self-expression and coping, individuals may turn to binge eating. 
The idea that binge eating functions as a method of cognitive avoidance has support within the literature. Prior to a binge eating episode, rigid, simplistic cognitive styles are typical (Lingswiler, Crowther, \& Stephens, 1989). This may indicate a preference toward cognitive blunting during binge eating episodes. More generally, research suggests that individuals with binge eating may prefer a dichotomous approach (e.g., an "all or nothing" framework) to processing intake-related cognitions (Grilo \& Shiffman, 1994). Given this cognitive style, eating and associated cognitions may be more likely to occur in a polarized fashion. Therapeutic interventions designed to produce cognitive and behavioral flexibility, and which challenge the use of avoidance as a coping strategy, (i.e., cognitive-behavioral therapy), have shown successful outcomes for the treatment of binge eating (Brownley, Berkman, Sedway, Lohr, \& Bulik, 2007; Lynch et al., 2010).

Research supports the theoretical notion that binge eating serves to reduce negative emotional states. Empirical study has found that negative affect, including specific factors such as worry, guilt and anger, often serves as a trigger of binge eating episodes (Napolitano \& Himes, 2011; Stein et al., 2007). Examinations of the "escape from awareness" model have demonstrated support for binge eating as a method of coping with negative affect (Engelberg, Steiger, Gauvin, \& Wonderlich, 2007). Neurological evidence has also demonstrated support for this model. In particular, research has suggested some types of overeating experiences may be linked to reduction of amygdala activity (Gautier et al., 2001).

Although binge eating may be somewhat successful as a coping strategy in that it produces a momentary reduction in negative affect (Deaver, Miltenberger, Smyth, 
Meidinger, \& Crosby, 2003), it is not an effective long range strategy for affect regulation. That is, negative mood is shown to increase after binge eating (Grilo \& Shiffman, 1994; Stein et al., 2007). Similarly, neurological evidence suggests that dopaminergic activity decreases following a satisfying eating experience, suggesting that depressive affect may follow binge eating episodes (Gautier et al., 2001). As such, binge eating may be self-perpetuating and lead to decreased self-efficacy in regard to coping. It has been suggested that repeated binge eating is more likely to occur when loss of control over eating is ascribed to fixed, internal factors. Similarly, these factors may also be associated with shorter interims between binge eating episodes (Grilo \& Shiffman, 1994). Previously published research has not examined specific components of negative affect (e.g., anxiety, depression) in their relation to binge eating. Therefore, it remains unknown whether specific components of negative affect have unique associations with binge eating that may differentially impact its development or maintenance.

\section{Binge Eating and Psychological Functioning}

Individuals with binge eating are at an increased risk for psychological impairment (Grucza et al., 2007; Yanovski, Nelson, Dubbert, \& Spitzer, 1993). Some research supports a linear association between psychological impairment and binge eating severity (Spindler \& Milos, 2007). In addition to decreasing quality of life among individuals with binge eating, psychological impairments have other important clinical consequences. Poor response to binge eating interventions has been primarily predicted by the presence of comorbid psychological disorders (Fichter, Quadflieg, \& Hedlund, 2008). 
Axis I disorders are prevalent among individuals with binge eating. Approximately $64 \%-79 \%$ of individuals with binge eating have been diagnosed with an Axis I disorder at some point in their lives (Grilo, White, \& Masheb, 2009; Hudson et al., 2007). The most common comorbid diagnoses are mood disorders and anxiety disorders, however there is some disagreement as to which group of diagnoses has higher lifetime prevalence rates. Some studies have found higher lifetime prevalence rates of mood disorders (i.e., 54\% - 61\%) (Grilo et al., 2009) while others have found higher rates of anxiety disorders (i.e., 65\%) (Hudson et al., 2007). The rates of current anxiety disorders are higher than current mood disorders among those with BED (Grilo, White, Barnes, \& Masheb, 2013). Overall, comorbid mood and anxiety disorders and are higher than those found among individuals without binge eating (Javaras et al., 2008; ReichbornKjennerud, Bulik, Sullivan, et al., 2004).

Much of the existing literature has focused on the relation of depression and binge eating. It may be that this emphasis has been imposed upon the field, in part, by the inclusion of depressive affect or guilt (following a binge eating episode) as an associated feature in the diagnostic criteria for BED (American Psychiatric Assocation, 2000). This emphasis is not without justification. Indeed, major depression has been consistently associated with binge eating in the literature as a common comorbidity (Grilo et al., 2009; Javaras et al., 2008; Wilfley et al., 2000). Elevations of depressive symptoms are common among individuals with binge eating (Pinaquy et al., 2003; Smith, Marcus, Lewis, Fitzgibbon, \& Schreiner, 1998; Telch \& Stice, 1998; Yanovski et al., 1993). Further, a linear association between depressive symptoms and binge eating severity has been supported by the literature (Azarbad et al., 2010; Mazzeo, Saunders, \& Mitchell, 
2006). It is important to note however that some have failed to identify an association between depression and binge eating (De Zwaan et al., 2003) and that others have found similar relations between anxiety and binge eating (Pinaquy et al., 2003).

There is support for further examination of comorbid anxiety disorders among individuals with binge eating. In general, rates of anxiety symptoms are higher among individuals with binge eating than those without (Mussell et al., 1996; Yanovski et al., 1993). In fact, women who have engaged in binge eating are 1.7 times more likely to report anxiety than those who have not had a binge eating episode (Bulik, Sullivan, \& Kendler, 2002). Similarly, the odds of specific anxiety diagnoses (i.e., generalized anxiety disorder and panic disorder) are higher for those with binge eating than those without (Grucza et al., 2007). Longitudinal research indicates the relation between binge eating and anxiety may extend for five years or more (Tanofsky-Kraff et al., 2011). Furthermore, genetic data indicate an increased risk for anxiety symptoms among individuals with binge eating (Reichborn-Kjennerud, Bulik, Sullivan, et al., 2004), and among first-degree relatives of those with binge eating (Lilenfeld, Ringham, Kalarchian, \& Marcus, 2008).

\section{Anxiety, Stress, and Binge Eating}

Empirically supported theory suggests negative affect may be closely related to the experience of binge eating. Much of the research that has examined the relation of negative affect and binge eating has focused exclusively on the role of depression.

Despite this emphasis on depression in the literature, there is reason to believe that other elements of negative affect (e.g., anxiety) may also have important contributions to the understanding of binge eating. In fact, the DSM-IV outlines that binge eating may be 
triggered by negative emotional states, broadly, and specifies anxiety as one such trigger (American Psychiatric Assocation, 2000). Further, the DSM-IV indicates that binge eating may be used by some to relieve generalized tension (i.e., stress) (American Psychiatric Assocation, 2000).

To date, there is limited published research examining the unique role that anxiety may have in the occurrence of binge eating. There are however, some reports that binge eating may have a particularly strong association with anxiety and serve to facilitate coping with this experience for some (Binford et al., 2004; Mitchell et al., 1999). It has been suggested that binge eating serves to limit the degree to which distressing, anxietyrelated stimuli enter into awareness (Pallister \& Waller, 2008). This is supported by research demonstrating that binge eating is associated with a reduction in anxiety (Fairburn, Cooper, \& Cooper, 1986), particularly among individuals with BED (Mitchell et al., 1999).

It has been proposed that anxiety may be related to binge eating either by functioning as a risk factor for binge eating or though shared vulnerability factors (Godart et al., 2003). Anxiety has been thought to frequently precede disordered eating behaviors (Pallister \& Waller, 2008). Evidence supports a temporal relation between anxiety and eating disorder diagnoses; over $50 \%$ of women with eating disorders experienced a clinically significant anxiety disorder prior to their developing disordered eating patterns (Godart et al., 2003). Similarly, shared vulnerability factors, such as stress, have been shown to impact the development of anxiety and binge eating (Gluck, 2006; Loth, van den Berg, Eisenberg, \& Neumark-Sztainer, 2008; McLaren \& Crowe, 2003; StriegelMoore \& Bulik, 2007). 
An association between stress and binge eating has been supported, independent of its role as a potential vulnerability factor (Azarbad et al., 2010; Woods, Racine, \& Klump, 2010). Notably, emotion-focused coping has been shown to partially mediate this relation (Sulkowski, Dempsey, \& Dempsey, 2011), suggesting that the association between stress and binge eating may be complex and involve emotional experiences. Empirical study suggests that stress impacts eating behavior, leading to increased intake for some (Torres \& Nowson, 2007). Well-controlled laboratory studies have shown that induced stress is linked to increased rate of eating and increased consumption of food among individuals with BED (Laessle \& Schulz, 2009). This relationship extends beyond the mere pattern of oral gratification as chronic stress is associated with a preference for eating highly caloric foods, such as those typical of a binge eating episode (Torres \& Nowson, 2007).

There is evidence to suggest that individuals with binge eating find stress to be more severe and more emotionally-draining than those that do not have binge eating (Crowther, Sanftner, Bonifazi, \& Shepherd, 2001). The relation between stress and binge eating has been shown to function independent of depression in some previous research. Specifically, higher stress was related to increased risk for binge eating on a given day, regardless of depressive affect (Freeman \& Gil, 2004). Additional studies are needed to replicate these findings.

The relation between stress and anxiety is well established in the literature. Importantly, both of these factors have been linked to perceived control (Bergdahl \& Bergdahl, 2002; Rapee, Craske, Brown, \& Barlow, 1996; Sanderson, Rapee, \& Barlow, 1989), which is known to be altered during binge eating. This suggests these factors may 
have particular importance for the understanding of binge eating, which is defined in part by a loss of control. Further examination of other components of negative affect, such as anxiety and stress, is needed to expand upon the solid foundation of research focused on depression.

Research is needed to further understand the role that psychological factors, such as anxiety and stress, may have in relation to binge eating. While it is known that anxiety and stress may be associated with binge eating, few have examined their relation in conjunction with depression. Many studies have been self-described as broad examinations of psychological distress but have focused exclusively on symptoms of depression [e.g., (Darby, Hay, Mond, Rodgers, \& Owen, 2007; Mitchell \& Mazzeo, 2004)]. In order to truly understand the impact of specific components of negative affect, investigations must be expanded to include factors other than depression. Additional examination of the specific relations of anxiety and stress may have clinical implications, such as tailoring of treatments to increase effectiveness and prevent relapse. Research of this nature may also inform study of risk and resilience in relation to binge eating.

\section{The Current Study}

Research supports a relation between psychological factors and binge eating. Much of the literature has focused on the association between depression and binge eating; however, less is known about other psychological factors that have been theoretically linked to binge eating, including anxiety and stress. Anxiety and depression frequently co-occur in individuals and have been linked through the tripartite model as components of a larger construct of negative affect (Clark \& Watson, 1991). It has been demonstrated that anxiety, responses to stress, and depression have unique profiles 
however (Brown, Chorpita, \& Barlow, 1998; Craske et al., 2009), suggesting a need for investigation of their individualized impacts.

The primary aim of the current study was to examine the relation of specific psychological factors to BEB. The current research planned to replicate and extend previous studies that have found support for a relation between depression and binge eating. Further, the current study also examined the relation of binge eating and other psychological factors that have received less attention in the literature, namely anxiety and stress. This study is novel in that it was the first, to our knowledge, to examine the unique impact of anxiety and stress independently from depression.

\section{Hypotheses}

The following hypotheses were proposed:

1a. It was hypothesized that anxiety [as measured by the Depression Anxiety Stress Scales-Anxiety Subscale (DASS-A)] would be significantly positively related to binge eating behavior [as measured by the Eating Disorder Diagnostic Scale Symptom Composite-Binge Eating Subscale (EDDS)].

1b. It was hypothesized that depression [as measured by the DASS- Depression Subscale (DASS-D)] would be significantly positively related to binge eating behavior (as measured by the EDDS).

1c. It was hypothesized that anxiety (DASS-A) would be significantly positively related to binge eating behavior (EDDS) after accounting for depression (DASS-D). 
2a. It was hypothesized that stress [as measured by the Perceived Stress Scale Total Score (PSS)] would be significantly positively correlated with binge eating behavior (EDDS).

2b. It was hypothesized that stress (PSS) would be significantly positively related to binge eating behavior (EDDS) after accounting for depression (DASS-D).

3. It was hypothesized that a model containing stress (PSS), anxiety (DASS-A), and depression (DASS-D) would account for the most variance in binge eating behavior (EDDS). That is, a model containing stress, anxiety, and depression would account for more variance in binge eating behavior than a model containing depression alone.

The following secondary hypotheses were proposed:

4a. It was hypothesized that cognitive avoidance [as measured by the White Bear Suppression Inventory (WBSI)] will be significantly positively related to binge eating behavior (EDDS).

4b. It was hypothesized that the relation between anxiety (DASS-A) and binge eating behavior (EDDS) would be mediated by cognitive avoidance (WBSI).

5. It was hypothesized that hostility [as measured by the hostility subscale of the Positive and Negative Affect Schedule - Expanded Form (PANAS-X)] would be significantly positively related to binge eating behavior (EDDS). 


\section{Method}

\section{Design}

This study was a cross-sectional single group design.

\section{Participants}

Inclusion criteria were broad to facilitate recruitment of a true community sample. Specifically, inclusion criteria required all participants were at least 18 years of age and possessed English language fluency in order to be eligible for this study. Responses from individuals: a) residing outside of the United States, b) under the age of 18, and/or c) selfreporting psychosis (e.g., current diagnosis of schizophrenia) were excluded.

Additionally, individuals who provided responses that were determined to be invalid or random based on validity screening questions were excluded from analysis.

A total of 717 individuals responded to the recruitment advertisements to take part in this research study. Of those individuals, 539 consented to participate, and 511 research participants provided at least one piece of research data for this project. Of those 511, 75 participants were excluded for failure to meet study inclusion and/or exclusion criteria leaving a total sample size for this study of 436 research participants. See Figure 1 for a CONSORT diagram of recruitment.

Age, race, and ethnicity. Participants ranged from 18 to 72 years old $(M=33.4$, $S D=13.5)$. The self-reported racial and ethnic backgrounds of participants in this sample include greater diversity than the reported demographic characteristics of the United States (i.e., 75\% White) (U.S. Census Bureau). See Table 1 for more information on the racial and ethnic backgrounds of this sample. 
Region. Attempts were made to recruit a geographically diverse sample within the United States. An advertisement was placed on a general psychology research study participation page accessible to all regions of the United States. Additionally, advertisements were placed in the "Volunteers" section of the community-based website Craigslist.org in the following cities: St. Louis, Houston, New York City, San Francisco, Atlanta, San Diego, Philadelphia, Phoenix, and Boston. See Table 1 for information about participants' geographic regions and other demographic characteristics.

Sex. Both men and women were eligible for inclusion across the recruitment window. Recruitment spanned approximately 6 months. Targeted advertisements to recruit male participants were used in conjunction with general recruitment advertisements in the last half of the recruitment window as early estimates suggested a bias toward more female respondents. Specifically, after the first three months of open recruitment without targeted advertisements, the sample was approximately $79 \%$ female. The final sample, after oversampling for males, was approximately $62 \%$ female. Of note, three individuals self-reported as transgendered and accounted for slightly less than $1 \%$ of the sample.

\section{Measures}

Demographics. A self-report questionnaire assessed demographic variables including age, sex, race, relationship status, income, sexual orientation, employment status, educational attainment, geographic region (e.g., East Coast, Midwest, West Coast, Southwest, Southeast) and environment (e.g., rural, urban, suburban).

Medical and Psychological History. Relevant medical history was also obtained through self-report. Medical history included height, weight, relevant medical conditions, 
and current medications. Current and previous psychological diagnoses were also collected via self-report.

Depression and Anxiety. The Depression (DASS-D) and Anxiety (DASS-A) subscales of the Depression Anxiety Stress Scales (Lovibond \& Lovibond, 1995a) were used to measure depression and anxiety, respectively. The DASS is a 21 -item self-report questionnaire; each subscale is 7-items in length. Conventionally, subscales assess the severity of symptoms in each respective domain over the past week, however for the purposes of this study this prompt was changed to reflect symptoms over the past month. Participants responded to items using a Likert-type scale ranging from 0 (did not apply to me at all) to 3 (applied to me very much, or most of the time). The conventional phrasing of the DASS has demonstrated good internal consistency. Cronbach's $\alpha$ for depression and anxiety subscales range from .94 (clinical and non-clinical participants) to .88 (nonclinical volunteers) and .87 (clinical and non-clinical participants) to .82 (non-clinical volunteers) respectively. Reliability analyses suggested high internal consistency for the DASS-D $(\alpha=.92)$ and the DASS-A $(\alpha=.82)$ for the current sample. Test-retest reliability correlations for DASS-D and DASS-A are .71 and .79, respectively (Henry \& Crawford, 2005; Lovibond \& Lovibond, 1995a). The DASS-D demonstrates good concurrent validity with the Beck Depression Inventory $(r=.77)$ in a sample of male and female clinical outpatients. Similarly, the DASS-A is correlated .84 with the Beck Anxiety Inventory among outpatients diagnosed with depression or anxiety disorders (Antony, Bieling, Cox, Enns, \& Swinson, 1998). Generally speaking, the psychometric properties of this measure are strong (McDowell, 2006). 
Stress. The Perceived Stress Scale (PSS) is a 10-item self-report questionnaire assessing participants' perceptions of stress over the past month (Cohen, Kamarck, \& Mermelstein, 1983). Item responses use a 5-point Likert scale ranging from 0 (never) to 4 (very often). Some items are reverse scored. This scale demonstrates strong psychometric properties including concurrent and predictive validity and coefficient alpha reliability among male and female college undergraduates (Cronbach's $\alpha=.84$ ) and smoking cessation program participants (Cronbach's $\alpha=.86)$ (Cohen et al., 1983). The 10-item version was chosen for this study, as it has been demonstrated to have super psychometrics to other versions of this scale (Lee, 2012). Reliability analyses from the current sample suggested strong internal consistency $(\alpha=.87)$ for the PSS.

Avoidance. The White Bear Suppression Inventory (WBSI) is a 15-item selfreport measure of cognitive avoidance and thought suppression (Wegner \& Zanakos, 1994). Participants rate the extent to which they agree with an item using an alphabetical scale (A-E) that ranges from A (strongly disagree) to E (strongly agree). These ratings are converted to a numerical score ranging from 1 (strongly disagree) to 5 (strongly agree). An example of a typical item is "There are things I prefer not to think about." Internal consistency ranged from .87 to .89 and test-retest reliability ranged from .69 to .92 among non-clinical samples (Wegner \& Zanakos, 1994). The WBSI demonstrated very good internal consistency $(\alpha=.95)$ for the current sample. The WBSI demonstrates good concurrent validity, as it is correlated with other measures of experiential avoidances, such as the Acceptance and Action Questionnaire $[r$ range $=.44$ (nonclinical) - .50 (clinical patients in a partial hospitalization program)] (Hayes et al., 2004). 
Hostility. The Positive and Negative Affect Schedule - Expanded Form (PANAS-X) is a 60-item self-report measure of two higher order constructs (Positive affect; Negative affect) that contains 11 subscales assessing specific domains of these constructs. The hostility subscale of the PANAS-X (H-PANAS-X) is a 6-item self-report measure assessing the extent to which individuals have felt "angry, hostile, irritable, scornful, disgusted and loathing" over the past month (Watson \& Clark, 1994). Participants provide rankings using a Likert-type scale ranging from 1 (very slightly or not at all) to 5 (extremely). The hostility subscale has good internal consistency (Cronbach's $\alpha=.86$ ) within a non-clinical sample. The H-PANAS-X also has high convergent validity with other measures of this domain, such as the Anger-Hostility scale of the Profile Of Mood States $(r=.91)$, in a non-clinical sample. Similarly, in a nonclinical sample, the H-PANAS-X demonstrated good test-retest reliability $(r=.65)$ after two months (Watson \& Clark, 1994). The six-item hostility subscale of the PANAS-X showed strong internal consistency $(\alpha=.88)$ for the current sample.

Binge Eating. The Eating Disorder Diagnostic Scale (EDDS) is a 22-item selfreport measure of eating behaviors (Stice, Telch, \& Rizvi, 2000). Participants responded to items assessing symptoms of anorexia nervosa, bulimia nervosa, and binge eating disorder. Some items prompted participants to respond in a dichotomous fashion (i.e., yes/no) while others necessitated dimensional reporting. Stice, Telch and Rizvi suggest that the responses can be used to determine whether a participant meets clinical or subclinical diagnostic criteria or for one or more of the above-mentioned diagnoses. It is important to note however, the EDDS defines subclinical diagnoses as an instance in which an individual endorses a sufficient number of symptoms of the disorder to meet 
diagnostic criteria, but at least one is rated at the level of subclinical severity (Stice, Presnell, \& Spangler, 2002). It should be noted however that according to DSM-IV-TR this type of response would meet criteria for EDNOS (American Psychiatric Assocation, 2000) and may not be an accurate indicator of subclinical impairment. The EDDS has demonstrated good psychometrics, including diagnostic utility (Stice et al., 2000). Although the psychometrics of this measure were computed based on a female sample, previous research has supported its use with men (Dunn, Neighbors, \& Larimer, 2003; Whiteside et al., 2007).

Responses to the EDDS can also be standardized (to account for the differences in response formats) and summed to create a dimensional symptom composite score (Stice, Fisher, \& Martinez, 2004). This linear score is computed such that higher scores indicate greater eating pathology. The symptom composite has been previously tested with non-clinical populations (Stice \& Ragan, 2002). The symptom composite of the EDDS has demonstrated test-retest reliability $(r=.87)$, internal consistency (Cronbach's $\alpha=.89$ ), and convergent validity with other self-reported measures of disordered eating among a sample containing clinical and non-clinical females (Stice et al., 2000). It also has been shown to have sensitivity and predictive validity among a sample of non-clinical female undergraduates (Stice et al., 2004). Only the items that load onto binge eating disorder criteria were used to generate the symptom composite for this study. This method of creating a binge eating-specific symptom composite has been successfully used in previous research, with internal consistency at .84 among a sample of non-clinical men and women (Dunn et al., 2003). Reliability analyses from the current sample 
indicate adequate internal consistency $(\alpha=.76)$ for the binge-eating specific symptom composite.

\section{Procedure}

The Institutional Review Board at the University of Missouri - St. Louis, approved this study. Data were collected via online questionnaires. Online data collection was selected for this research because it allows for greater geographic heterogeneity in the sample, it may yield more candid reports to sensitive questions (Feigelson \& Dwight, 2000), and it minimizes participant burden. The questionnaire battery was hosted on a secure website (i.e., www.SurveyMonkey.com). Participants were provided with the informed consent document as the first page of the questionnaire battery. They were given the opportunity to read the Informed Consent Form that included the study procedures, limits of confidentiality, and a telephone number that they could call to reach the Principal Investigator should they have questions about the research study. Prior to beginning the questionnaire, participants reported their informed consent by clicking a confirmatory button.

Participants for this research were recruited through online advertisements, specifically electronic community bulletin boards (i.e., Craigslist, and an independent research recruitment board). These advertisements were posted in sites available to a variety of U.S. metropolitan regions in order to enhance geographic diversity in the sample. A link to the online questionnaire battery was included in the recruitment advertisement.

Participants were offered the chance to be included in a raffle drawing. Participants were directed to a separate screen at the completion of the questionnaire 
battery where they may submit their email address to be entered into the raffle. Seven raffles were held in August 2012, each with a prize of a $\$ 100$ gift card. The winners of the raffle received an electronic gift card code via email. No personal identifying information (e.g., name, physical address) was collected to process the compensation or for completion of any portion of the study. Email addresses collected for compensation purposes were stored separately from participants' questionnaire data to ensure confidentiality. Participants had the option of declining to provide an email address. Email addresses were destroyed after the raffle drawing in August 2012. Participants were asked to complete the questionnaire battery one time only. The estimated time for completion of the questionnaire battery was approximately 20 - 30 minutes.

Privacy and Risk Protection. The link to the online questionnaires was encrypted via Secure Sockets Layer (SSL) to ensure participants' privacy. This SSL encryption also protected participants' data during completion and transmission of individual sections of the questionnaire battery. In the interest of maintaining confidential data collection, participants' IP addresses were not collected. Access to participants' data on the hosting site was also limited through password protection.

All participants were provided with information to direct them to resources if they experienced distress during their participation, or were interested in follow-up referrals for mental health counseling. The telephone numbers for national crisis hotlines [e.g., National Suicide Prevention Lifeline at 1-800-273-TALK (1-800-273-8255)] and websites to direct participants to mental health treatment options (e.g., Mental Health America at http://www.nmha.org/) were provided.

\section{Data Analysis}


Data Storage. Data were exported directly from the online questionnaires into Microsoft Excel to minimize data entry errors. Questions designed to detect random responding were included in the battery. Those who responded incorrectly to more than one of these items were excluded from analyses on the basis of probable random responding (see Figure 1). Each set of usable responses was assigned a unique identifying number in the database. No personally identifying information were collected or stored with these data.

Power Analyses. A priori power analyses were conducted with alpha set a $p<$ .05 and power set at $80 \%$. First, in order to detect a significant result for correlational analyses used to test hypotheses 1a, 1b, 2a, 4a, and 5, 64 participants with analyzable data were needed for adequate power to detect a moderate effect $(r=0.30)$. Next, in order to detect a significant difference for the hierarchical regression analyses involving two predictors used to examine hypotheses $1 \mathrm{c}, 2 \mathrm{~b}$, and 4b, 68 participants were needed to detect a moderate effect $\left(f^{2}=0.15\right)$. Finally, to test hypothesis 3 , which included a hierarchical regression analysis involving three predictors, 77 participants with analyzable data were needed. In total, 77 participants with analyzable data were needed for this study. The total number of participants that provided analyzable data for hypothesis 3 was 313 . For the analysis with the greatest number of hypothesized predictors (i.e., hypothesis three), with 313 participants the power to detect a moderate effect $\left(f^{2}=0.15\right)$ was $99 \%$.

\section{Data Screening.}

Data were screened for outliers and to verify regression assumptions. First, data were screened for normal distribution and skewness. Next, homoscedasticity and 
multicollinearity were examined. Finally, data were assessed for completeness and missing data. Data were analyzed using SPSS (SPSS, 2006).

First, data were screened for outliers to protect against entry errors made by participants. Data from two individuals were also excluded following the outlier check due to an invalid response pattern. Normality of data was assessed via KolmogorovSmirnov tests with a null hypothesis of normal distribution, and histograms. These assessments indicated that the depression, anxiety, and binge eating symptom composite were positively skewed, due to the frequency of low symptom endorsement of these domains across the sample. Specifically, skewness for these data were 1.2, 1.3, and 0.68 for depression, anxiety and binge eating symptomology, respectively; KolmogorovSmirnov test $p<.05$ for all three measures. The perceived stress data were normally distributed (i.e., Kolmogorov-Smirnov test $p>.05$ ). The skewness for the perceived stress variable was 0.12 , which is within the range that is typically considered to follow a normal distribution (i.e., - 0.5 - 0.5). Data for skewed variables were not transformed due to the meaningfulness of "zero" responses for these clinically relevant symptom measures in this community-based sample.

Next, data were assessed for homoscedasticity and multicollinearity. Scatterplots of standardized residuals were used to assess homoscedasticity. Upon visual inspection, all relevant variables appeared to exhibit homoscedasticity. Multicollinearity was examined using variance inflation factor and tolerance statistics. The variance inflation factor (VIF) between depression and anxiety was 1.52. Some have suggested the range for concern for VIF to be somewhere between 5 and 10 (Allen, 1997; Hutcheson \& Sofroniou, 1999; York, 2012). A VIF of greater than 5 has been used as an indicator for 
further investigation for multicollinarity previously in eating behavior research (Lamarche \& Gammage, 2012). Therefore, according to current conventions within the field, the VIF of 1.52 in the present study well below the suggested range for concern. Similarly, tolerance was 0.66 , which is above the suggested range for concern (i.e., $<$ 0.2). Stress was also examined for multicollinearity with anxiety and depression. The variance inflation factor values between stress and anxiety (1.52) and between stress and depression (1.83) were below the suggested range for concern. Similarly, tolerance was 0.66 and 0.55 , respectively, which is above the suggested range for concern. Taken together, these analyses suggest these data were not impacted by multicollinearity.

Finally, data were screened for completeness. Questionnaires were excluded from analyses if they were less than $80 \%$ complete. For those with $80 \%$ to $99 \%$ completeness, mean imputation was performed to manage missing data.

\section{Results}

\section{Sample Characteristics and Descriptive Analyses}

Demographic Factors. Approximately 37\% of participants reported working full-time, $17 \%$ were employed part-time, $14 \%$ were unemployed, and approximately $21 \%$ were students. Other participants reported they were full-time homemakers $(4 \%)$, on disability (4\%), or retired (3\%). One fourth of the sample reported their annual household income as less than $\$ 15,000$. Approximately $41 \%$ of the sample reported completing a bachelor's degree or higher. 
In regard to relationship status, half of the sample reported they were single and never married. One fourth of the sample reported they were married, and about $14 \%$ reported they were partnered or living together. The remaining participants reported they were separated or divorced $(11 \%)$ or widowed $(<1 \%)$. The majority $(85 \%)$ of the sample self-identified their sexual orientation as heterosexual. Approximately $8 \%$ reported they were bisexual, $6.4 \%$ identified as gay or lesbian, $0.5 \%$ identified as queer, and $0.2 \%$ reported they identified in another way.

Self-reported Psychological and Medical Diagnoses. Approximately 31\% and $39 \%$ of participants reported a lifetime or current history of diagnosis of a mood disorder or anxiety disorder, respectively. Additionally, approximately $19 \%$ and $22 \%$ of participants reported current treatment for a mood disorder or anxiety disorder, respectively. The most commonly reported mood and anxiety disorders were Major Depressive Disorder (19.4\%) and Generalized Anxiety Disorder (13\%) respectively. In regard to relevant medical diagnoses, cardiovascular risk factors including hypertension and hyperlipidemia (both 19\%, respectively) were present in addition to overweight and obesity. The range of BMI in the current sample was $16.46-68.41$, and the average BMI fell within the overweight range $(M=27.5, S D=7.7)$. In total $(n=300)$, $5 \%(n=15)$ fell within the underweight range, $38.7 \%(n=116)$ fell within the normal weight range, $27.7 \%(n=83)$ fell within the overweight range, and $28.7 \%(n=86)$ fell within the obese range. Taken together, over half (56.4\%) of the sample was above a healthy weight. This is similar to the national average, in which $35.9 \%$ of adults are obese and 33.3\% are overweight (Centers for Disease Control and Prevention, 2012). 
Please refer to Table 2 for a history of participants' self-reported psychological and relevant medical diagnoses. This table also includes information on the diagnoses for which participants reported undergoing treatment at the time of survey completion.

\section{Descriptive Analyses for Study Variables}

In general, women reported statistically significantly higher scores on all study measures, except depression. General descriptive information (i.e., mean and standard deviation) for key study variables, including anxiety, depression, stress, and binge eating symptom composite scores, are reported for women, men, and the full sample, in Table 3.

Depression. The DASS-D scores for this study ranged from 0 - 42, with higher scores indicating greater depression. The modal score for this variable was zero, as reflected in the positive skew. Including this tendency toward zero responses, the average depression symptoms endorsed $(M=10.91, S D=11.3)$, were substantially greater than those reported in non-clinical volunteer samples $(M=2.12-3.87, S D=3.64-3.98)$ (Antony et al., 1998; Osman et al., 2012). The depression symptoms reported across this sample, while lower than those endorsed among those with Major Depressive Disorder $(M=29.96, S D=9.18)$, are similar to those found among samples with clinically significant anxiety $(M=10.82, S D=11.25)$ (Antony et al., 1998). According to the DASS manual, the average level of depression endorsed by this sample, including those who reported no symptoms, falls within the mild range (Lovibond \& Lovibond, 1995a). Approximately $35 \%$ of the sample endorsed depression symptoms at or above a moderate level; approximately $18 \%$ reported symptoms classified in the severe range (Lovibond \& Lovibond, 1995a). 
Anxiety. The DASS-A scores for this study ranged from 0 - 38, with higher scores reflecting greater anxiety. Similar to the depression data presented above, although the modal score for this measure was zero, average levels of anxiety reported for this sample $(M=7.56, S D=8.15)$ were substantially higher than those reported for nonclinical volunteers $(M=1.22-3.18, S D=1.77$ - 3.38) (Antony et al., 1998; Osman et al., 2012). In fact, the current data reflects anxiety levels similar to those found among samples with clinically significant anxiety (e.g., $M=6.59-9.26, S D=6.59-7.56$ ) (Antony et al., 1998). According to the DASS manual, the average level of anxiety endorsed across this sample falls within the mild range (Lovibond \& Lovibond, 1995a). Approximately $34 \%$ of the sample endorsed anxiety levels that are classified within or above the moderate range; of these, approximately $18 \%$ of the sample endorsed anxiety within the severe range (Lovibond \& Lovibond, 1995a), reflecting a range of symptoms.

Perceived Stress. The current community-based sample reported similar levels of perceived stress $(M=18.33, S D=8.46)$, compared to a recent large-scale national sample of men $(M=15.52, S D=7.44)$ and women $(M=16.14, S D=7.56)($ Cohen $\&$ Janicki-Deverts, 2012).

Binge Eating Symptoms. Approximately $6.8 \%(n=21)$ of those who responded to the binge eating measure $(n=308)$ endorsed levels of binge eating symptoms that were consistent with DSM-IV-TR criteria for clinically significant BED. Additionally, $6.5 \%$ ( $n$ $=20$ ) endorsed subclinical binge eating disorder symptoms (BEB). For this study, BEB was defined as endorsement of eating an unusually large amount of food given the circumstances within the past 6 months, accompanied by a loss of control, in the absence of purging behaviors. Refer to Figure 2 for a graph of binge eating prevalence. These data 
suggest similar levels of binge eating prevalence to those reported in other community samples (Grilo, 2002; Grucza et al., 2007; Hudson et al., 2007; Spitzer et al., 1992). Although the binge eating symptom composite has been used in previous research (Dunn et al., 2003), there are no known published descriptive data for community or clinical samples for this subsection of the EDDS.

Hostility. Total hostility scores ranged from 6 - 30, with higher scores indicating more hostility. This sample reported similar levels of hostility over the past month $(M=$ $13.2, S D=5.6)$ compared to an undergraduate normative sample $(M=12.3, S D=4.8)$ (Watson \& Clark, 1994).

Cognitive Avoidance. The score on this measure for this study ranged from 15 75, with higher scores reflecting greater cognitive avoidance. On average, this sample reported similar levels of cognitive avoidance $(M=47.6, S D=16.23)$ to those reported among a normative comparison group of undergraduates $\left(M_{\text {men }}=43.4, M_{\text {women }}=47.6\right.$, $S D=10.18)$ (Wegner \& Zanakos, 1994).

\section{Primary Analyses}

Hypothesis 1a. To determine the relation between anxiety and binge eating symptoms, a Pearson's $r$ correlation was calculated using the DASS-A and EDDS Binge Eating Symptom Composite. A significant relation was observed in this analysis $(r=$ $0.33, p=0.000)$. This correlation coefficient was consistent with a medium effect size. Greater anxiety was associated with greater binge eating symptoms. This analysis supported hypothesis 1a.

Hypothesis 1b. The relation between depression and binge eating symptoms was also examined using a Pearson's $r$ correlation. The scores from the DASS-D and EDDS 
Binge Eating Symptom Composite were used for this equation. Depression and binge eating symptoms were significantly related, with a correlation coefficient consistent with a small effect size $(r=0.20 p=0.000)$. Greater depression was associated with greater binge eating symptoms. This analysis supported hypothesis $1 \mathrm{~b}$.

Hypothesis 1c. To determine the relation of anxiety and binge eating symptoms after accounting for depression, a hierarchical multiple regression analysis was conducted. Due to the significant difference between women and men in binge eating symptoms, the first step of this model controlled for gender effects. Depression was the first hypothesized predictor variable entered into the model. Depression was a significant predictor of binge eating in the second step of the model $\left(\beta=0.20, p=0.000, f^{2}=0.06\right)$. Anxiety was entered in the third and final step of the model, and was a significant predictor of binge eating symptoms $\left(\beta=0.30, p=0.000, f^{2}=0.14\right)$. After anxiety was entered in the final block, depression showed a reduction in beta weight and was no longer a significant predictor $(\beta=0.02, p=0.72)$. The final model was a good fit to the data $F(3,312)=13.3, p=.000$. Anxiety contributed to extent to which binge eating symptoms were accounted for by the model, the effect size observed at the final step was small, approaching the medium range (i.e., 0.15). Anxiety accounted for more of the variance in binge eating symptoms than depression, supporting hypothesis $1 \mathrm{c}$.

Hypothesis 2a. The relation between stress and binge eating symptoms was examined using a Pearson's $r$ correlation using the PSS and EDDS Binge Eating Symptom Composite. A significant relation was found $(r=0.31, p=0.000)$. The correlation coefficient observed in this analysis was consistent with a medium effect size. 
Hypothesis 2a was supported; higher stress was associated with higher binge eating symptoms.

Hypothesis 2b. A hierarchical multiple regression analysis was used to determine the relation of stress to binge eating symptoms after accounting for depression. Due to the significant gender difference in binge eating symptoms, gender was entered into the model first to control for its effects. Depression was entered into the model next to control for its effect on binge eating symptoms $\left(\beta=0.20, p=0.000, f^{2}=0.06\right)$. Following this step, stress was entered into the model, and was significantly associated with binge eating symptoms $(\beta=0.31, p=0.000$. Following the addition of stress in the final step of the model the beta weight of depression was reduced and was no longer a significant predictor $(\beta=-0.005, p=0.95)$. The final model was a good fit to the data $\left.F(3,312)=11.8, p=.000, f^{2}=0.11\right)$. Stress accounted for more of the variance in binge eating symptoms than depression, supporting hypothesis $2 b$.

Hypothesis 3. A hierarchical multiple regression analysis was used to determine whether a model containing anxiety, stress, and depression explained more of the variance in binge eating symptoms than a model containing only depression. Gender was entered first into the model to account for the significant differences in binge eating symptoms between men and women. Depression was entered into the second step of the model $(\beta=0.20, p=0.000)$. A small effect was observed $\left(f^{2}=0.06\right)$. Next, both anxiety $(\beta=0.25, p=0.003)$ and stress $(\beta=0.22, p=0.004)$ were entered into the final block of the model. After the addition of anxiety and stress, depression experienced a reduction in beta weight and was no longer a significant predictor of binge eating symptoms $(\beta=$ $0.09, p=0.23$ ). The final model containing depression, anxiety, and stress was significant 
$[F(4,308)=12.4, p=.000]$ with a medium effect $\left(f^{2}=0.16\right)$. The $F$ change at final step (14.98) was significant at $p=.000$. The change in $R^{2}$ between the second and final steps of the model was 0.08 . The final model explained more of the variance in binge eating symptoms than a model containing depression alone. The effect size of the final model was greater than the effect size of the depression-only model. Hypothesis 3 was supported by these results.

\section{Secondary Analyses}

Hypothesis 4a. The relation between cognitive avoidance and binge eating symptoms was examined using a Pearson's $r$ correlation using the WBSI and EDDS Binge Eating Symptom Composite. A significant relation was found $(r=0.30, p=$ 0.000). This correlation coefficient was consistent with a medium effect size. Hypothesis 4a was supported; greater binge eating symptoms were significantly associated with greater cognitive avoidance.

Hypothesis 4b. Hierarchical regression analyses were carried out following Baron and Kenny's (1986) recommendations for mediation. The binge eating symptom composite was entered as the dependent variable. Sex was entered in the first step of the model to control for gender effects. Anxiety was entered into the next step of the model and was observed to be a significant predictor $(\beta=0.32, p=0.000)$ of binge eating symptoms. Next, cognitive avoidance was entered into to the model test for mediation. Cognitive avoidance emerged as a significant predictor $(\beta=0.19, p=0.004)$. After the addition of cognitive avoidance, the anxiety variable showed a reduction in beta weight $(\beta=0.24)$ but remained a significant predictor $(p=0.000)$. Additionally, a Sobel test was performed to test for indirect effects. The Sobel value of $2.85(p=0.004)$, supported 
partial mediation, with the percentage of the total effect that was mediated equaling approximately $27.1 \%$. Hypothesis $4 \mathrm{~b}$ was supported by these results. Cognitive avoidance partially mediated the relation of anxiety and binge eating symptoms.

Hypothesis 5. The relation between hostility and binge eating symptoms was tested using a Pearson's $r$ correlation using the H-PANAS-X and EDDS Binge Eating Symptom Composite. This correlation was significant $(r=0.36, p=0.000)$. This correlation coefficient was consistent with a medium effect size. Greater hostility was associated with greater binge eating symptoms, indicating support for hypothesis 5 .

Secondary Analyses to Examine Gender Differences. A set of secondary analyses was conducted post hoc to contextualize and better understand the possibility of a gender effect on these results and study variables.

Hypothesis 1c by Gender. To investigate the possibility of a gender effect, hypothesis 1c was run separately by gender, for men $(n=113)$ and for women $(n=197)$. When the analysis was examined by gender subgroup, the findings remained significant and consistent across genders. For men, depression was a significant predictor at the first step of the model $(\beta=0.24, p=0.01)$. When anxiety was entered in the second step of the model, the beta weight of depression was reduced, and it was no longer a significant predictor of binge eating symptoms for men $(\beta=-0.08, p=0.45)$. Anxiety was a significant predictor of binge eating symptoms in the final block for men $(\beta=0.52, p=$ 0.000). For women, depression was also a significant predictor at the first step of the model $(\beta=0.18, p=0.01)$. When anxiety was entered in the second block of the model, the beta weight of depression was reduced, and it was no longer a significant predictor of binge eating symptoms for women $(\beta=0.05, p=0.53)$. Anxiety was a significant 
predictor of binge eating in the final block for women $(\beta=0.22, p=0.01)$. A medium effect was observed for the model containing only men $\left(f^{2}=0.28\right)$, and a small effect was observed in the model containing only women $\left(f^{2}=0.06\right)$.

Hypothesis 2 b by Gender. Hypothesis $2 \mathrm{~b}$ was also run separately, for men $(n=$ 113 ) and for women $(n=197)$. Depression was entered first into the models and was a significant predictor of binge eating symptoms for men $(\beta=0.24, p=0.01)$ and for women $(\beta=0.18, p=0.01)$. When anxiety was entered in the second block, the beta weight of depression was reduced and it was no longer a significant predictor of binge eating symptoms for men $(\beta=0.06, p=0.63)$ and for women $(\beta=-0.03, p=0.73)$. At the final step of the model, there was a trend for anxiety to serve as a significant predictor of binge eating symptoms for men $(\beta=0.24, p=0.08)$. Anxiety was a strong predictor of binge eating symptoms for women $(\beta=0.32, p=0.000)$. Small effects were observed for the model containing only men $\left(f^{2}=0.09\right)$, and in the model containing only women $\left(f^{2}=\right.$ $0.09)$.

Hypothesis 3 by Gender. Analyses for hypothesis 3 were run separately for men and women to examine the potential of a gender effect. The results from the first subsample, containing only men, differed from the combined gender sample. Depression was entered into the first step of the model, and was a significant predictor $(\beta=0.24, p=$ $\left.0.01, f^{2}=0.06\right)$. Anxiety and stress were entered into the second block of the model. At this step, anxiety emerged as a significant predictor $(\beta=0.50, p=0.000)$. Additionally, depression experienced a reduction in beta weight and was no longer a significant predictor of binge eating symptoms $(\beta=-0.13, p=0.34)$. Notably, in this step of the model, stress was not a significant predictor of binge eating symptoms $(\beta=0.08, p=$ 
0.55). While depression and stress were not significant predictors, the final model containing all three negative affect variables was significant $[F(3,112)=10.4, p=.000]$ with a robust medium effect $\left(f^{2}=0.28\right)$. The $F$ change at final step (11.5) was significant $p=.000$. The change in $R^{2}$ between the first and final steps of the model was 0.16 . The final model containing all three negative affect variables explained $16 \%$ more of the variance in binge eating symptoms than a model containing depression alone, among men.

The results for the female subsample differed from the combined gender sample, and from the results of the male subsample. Depression was entered into the first step of the model, and was a significant predictor of binge eating symptoms $(\beta=0.18, p$ $\left.=0.01, f^{2}=0.03\right)$. The second step of the model contained anxiety and stress. Again, similar to the results observed in previous analyses, depression experienced a reduction in beta weight $(\beta=-0.08, p=0.40)$. Anxiety was not significant at this step $(\beta=0.14, p=$ $0.12)$; however, stress was a significant predictor of binge eating symptoms $(\beta=0.28, p=$ 0.004). The final model containing all three negative affect variables was significant $[F(3,196)=7.5, p=.000]$ with a small effect $\left(f^{2}=0.11\right)$. The $F$ change at final step $(7.8)$ was significant $p=.001$. The change in $R^{2}$ between the first and final steps of the model was 0.07 , indicating that the inclusion of stress and anxiety accounted for $7 \%$ more of the variance in binge eating symptoms.

Hypothesis 4 b by Gender. The mediation analysis was performed separately for men and women to examine the possibility of a gender effect. For the subsample of men $(n=89)$, anxiety emerged as a significant predictor of binge eating symptoms in the first 
step $(\beta=0.53, p=0.000)$. When cognitive avoidance was entered in the second block, it was not significant $(\beta=-0.01, p=0.91)$, and mediation was not supported.

For the subsample of women $(n=172)$, a robust mediation effect was observed. Anxiety was entered in the first step and was as a significant predictor of binge eating symptoms $(\beta=0.22, p=0.003)$. Next, cognitive avoidance was entered into the model, and was a significant predictor $(\beta=0.28, p=0.001)$. After the inclusion of cognitive avoidance this step, anxiety experienced a reduction in beta weight $(\beta=0.10)$, and was no longer a significant predictor of binge eating symptoms $(p=0.23)$. The Sobel value of $3.76(p=0.000)$, supported mediation, with the percentage of the total effect that was mediated equaling approximately 50.2\%.

Hypothesis 5 by Gender. The relation between hostility and binge eating was examined separately for men and women. For men $(n=93)$, the relation between these two variables was stronger than in the combined gender sample, and remained significant, approaching a large effect $(r=0.47, p=0.000)$. For women $(n=183)$, the relation between hostility and binge eating symptoms remained significant, however relation was less robust than what was observed in the subsample of men, and approached a medium effect size $(r=0.29, p=0.000)$. Despite the difference in effect size, there was not a significant difference in the correlation between hostility and binge eating symptoms between genders $(z=-1.64, p=0.10)$.

\section{Discussion}

\section{Overview}

The current study sought to contribute to the existing literature by examining binge eating symptoms in their relation to anxiety, in addition to their relation to other 
negative emotional states (e.g., depression and stress). The findings of this study are discussed in the context of the previous literature below.

Prevalence of binge eating and range of psychological factors. In this study, we found rates of BED that are consistent with some previous community basedestimates [i.e., (Grucza et al., 2007)], and slightly higher than others estimates (Bruce \& Agras, 1992; Hudson et al., 2007). Subclinical binge eating, as defined for this study, was higher than previous community-based estimates (Bruce \& Agras, 1992; Hudson et al., 2007). It is important to note that the due to the large-scale nature of community-based prevalence studies, many prevalence estimates, including the ones obtained in the current study, do not include clinician-administered interview measures. Clinician-administered interview measures are a preferred method of facilitating accurate diagnoses, and as such, it is important to interpret these prevalence estimates with caution.

Additionally, it is difficult to understand the higher rates of subclinical binge eating noted in the current sample within a larger context, as much of the existing literature has focused on clinically significant binge eating. It may be that the current study was able to more accurately approximate the true prevalence of subclinical binge eating than previous studies due to the demographic and geographic diversity of this broad-based sample. Additionally, a sizable portion of respondents reported anxiety and depression symptoms at or above the moderate range. The prevalence of anxiety and depression symptoms in the subclinical and clinical ranges may suggest a greater likelihood of subclinical and clinical binge eating for this sample. Moreover, definitions of subclinical binge eating have differed in the literature over time, which may complicate comparisons across samples. 
In regard to anxiety and depression, on average, the psychological distress reported across this sample was classified as mild. A range of severity was noted however, with substantial portions of the sample reporting anxiety and depression consistent with moderate and severe levels (Lovibond \& Lovibond, 1995a).

Anxiety, Depression, and Binge Eating. Negative affect has been theorized as a primary factor in the syndrome of binge eating (Heatherton \& Baumeister, 1991). Further, empirical evidence has emerged to support this theory (Greeno, Wing, \& Shiffman, 2000; Pollert et al., 2013; Stein et al., 2007) Both depression and anxiety are theorized to share a component of generalized negative emotional distress, or negative affect (Clark \& Watson, 1991); however, in the binge eating literature, examinations of negative affect have often focused on depression. Some findings support depression as the most prevalent comorbidity of BED (Grilo et al., 2009; Javaras et al., 2008; Wilfley et al., 2000), which may partially explain why, to date, few studies have empirically examined the importance of anxiety in relation to BED. Overall, there still exists a need for greater understanding of the role of anxiety in binge eating, broadly.

The current study also examined the role of cognitive avoidance in the relation between anxiety and binge eating. Binge eating has been theorized as a method of “escape” from negative emotional states, such as anxiety (Heatherton \& Baumeister, 1991). Some empirical evidence supports the conceptualization of binge eating as a method of coping with negative emotional states (Binford et al., 2004; Sierra-Baigrie, Lemos-Giráldez, Paino, \& Fonseca-Pedrero, 2012; Sulkowski et al., 2011); however, the literature specifically examining the relation of cognitive avoidance and anxiety to binge 
eating symptoms is in need of expansion. The current study furthers the understanding of the role of cognitive avoidance in the relation of anxiety and binge eating.

This study examined the relation between two primary aspects of negative affect, namely anxiety and depression, and binge eating. Several theories have agreed that binge eating may occur following an exacerbation of negative affect (Fairburn, 2008;

Heatherton \& Baumeister, 1991; Sherry \& Hall, 2009). The results of this study build upon, and compliment, the existing literature that has examined the relation between negative affect and binge eating broadly via measures of generalized negative emotionality, and generalized distress (Goldschmidt et al., 2012; Greeno et al., 2000; Stein et al., 2007). The more specific analyses of this study examining anxiety, depression, and binge eating support previous studies that have found a relation between depression and binge eating (Azarbad et al., 2010; Mazzeo et al., 2006; Pinaquy et al., 2003), as well as those that have found a relation between anxiety and binge eating (Ostrovsky, Swencionis, Wylie-Rosett, \& Isasi, 2013; Pokrajac-Bulian, Tkalčić, \& Ambrosi-Randić, 2013).

The current study is unique because it provides the first known direct test of the independent relation of anxiety to binge eating, after accounting for the contributions of depression. The extent to which anxiety relates to binge eating after accounting for depression is an important, yet under-examined, inquiry as theory suggests that individuals may engage in binge eating to limit the extent to which aversive, negative emotions, receive cognitive priority (Heatherton \& Baumeister, 1991). The negative emotion from which individuals engaged in binge eating are "escaping" has been previously conceptualized as depression (Paxton \& Diggens, 1997); however, the results 
of this study suggest that anxiety may have a larger role in the "escape" process than what the contemporary literature has appreciated to date. In fact, these data suggest that anxiety serves a primary role, accounting for a larger proportion of the variance in binge eating symptoms than depression. Indeed, as demonstrated through the analyses in this study, when both anxiety and depression are examined in relation to binge eating symptoms, anxiety emerges as the stronger predictor.

The results of the current study are consistent with a recent study that found a strong cross-sectional correlation between symptoms of anxiety and binge eating, but not between depression and binge eating (Pokrajac-Bulian et al., 2013). Similarly, these results are in agreement with a recently published report which notes that anxiety disorders are the most common current comorbid psychological disorders with BED, exceeding the prevalence of current comorbid mood disorders and BED (Grilo et al., 2013). In sum, the results of the current study compliment the extension of negative affect-related binge eating investigations in the literature, and add support to the growing literature recognizing the unique role of anxiety in BED.

Stress, Depression, and Binge Eating. This study examined the relation between stress and binge eating symptoms, independently, and in conjunction with depression. The literature to date has supported a relation between stress and binge eating (Azarbad et al., 2010; Laessle \& Schulz, 2009; Woods et al., 2010). The data from the current study are consistent with these previous findings, and suggest a robust relation between stress and binge eating symptoms. Further, these data may be interpreted as extending the literature regarding negative affect and binge eating broadly. Additionally, these data support continued investigation of more specific questions regarding the nature of the 
relation between stress and binge eating, including the possibility of biological dysregulation of stress systems in individuals with BED (Rosenberg et al., in press).

A strength of the current study is its examination of the relation of stress and binge eating symptoms after taking into account the influence of depression. The results of this study suggest that when both stress and depression are examined together in relation to binge eating symptoms, the role of depression is superseded by the importance of stress. Previous research has found that stress incurs increased risk for a binge eating episode, independent of depression (Freeman \& Gil, 2004). Although the current study is not able to examine risk per se, it supports the notion that stress has a unique and powerful impact on binge eating.

Anxiety, Depression, Stress, and Binge Eating. This study examined whether the inclusion of anxiety and stress added unique contributions to the relation of depression and binge eating symptoms. These data support the notion that that a model containing several aspects of negative affect has a stronger relation to binge eating, than a model containing depression alone. Furthermore, when examined together, both anxiety and stress have stronger relation to binge eating symptoms than depression alone. This finding was not only significant, but also demonstrated a robust effect. This suggests that this result is not simply attributable to the inclusion of additional predictors to the model. Rather, anxiety and depression have unique and meaningful contributions in this model.

When understood in the context of the existing literature, this finding suggests that examinations of negative affect in relation to binge eating may benefit from inclusion of the full construct in measurement selection. That is, while some previous research studies may have conceptualized research questions, and discussed the associated 
findings, in regard to negative affect broadly, measurement of depression has often been the focus in the methodology (Darby et al., 2007; Dingemans, Martijn, Jansen, \& van Furth, 2009; Mitchell \& Mazzeo, 2004; Paxton \& Diggens, 1997). The data from the current study suggest that the strength of association observed in the literature between depression and binge eating may be partially attributed to the omission of measures of anxiety and stress in the methodology at large. Indeed, these data support continued examination of negative affect as a construct rather than a proxy for depression.

Cognitive Avoidance, Anxiety, and Binge Eating. Theory has conceptualized binge eating in the context of facilitation of cognitive avoidance in response to strong negative emotionality (Heatherton \& Baumeister, 1991). To date, research supporting this theory has largely focused on the relation of negative emotionality and binge eating behavior (Kaye, Gwirtsman, George, Weiss, \& Jimerson, 1986; Stein et al., 2007; Stickney, Miltenberger, \& Wolff, 1999; Whiteside et al., 2007) extrapolating support for the process of cognitive avoidance, while direct examinations of the relation between the construct of cognitive avoidance and binge eating have been less common (Blackburn, Johnston, Blampied, Popp, \& Kallen, 2006) (Paxton \& Diggens, 1997). This study examined cognitive avoidance and binge eating symptoms directly, and found a strong, significant relation. This finding supports the cognitive avoidance theory of binge eating (Heatherton \& Baumeister, 1991), and suggests that binge eating may be more likely to occur without appreciation for the proximal and distal consequences of this behavior.

This study examined the role of cognitive avoidance as a mediator of the relation between anxiety and binge eating symptoms. The results of this analysis favor cognitive avoidance as a partial mediator. This suggests that cognitive avoidance may be 
responsible for some of the relation between anxiety and binge eating, however the direct link between anxiety and binge eating symptoms remains strong and is not completely accounted for by cognitive avoidance. It may be that cognitive avoidance has a meaningful impact on binge eating symptoms, however anxiety has a strong direct effect on binge eating symptoms that is not completely expressed through the process of cognitive avoidance.

While the relations of anxiety and cognitive avoidance have been examined in regard to binge eating previously, this has not been within the context of BED (Lingswiler et al., 1989; Meyer et al., 2005). The data from the current study extend the applicability of previous anxiety and binge eating analyses to a broader context of clinical and subclinical binge eating disorder. Moreover, because these data were collected from a diverse community-based sample, these results suggest a more generalizable relation may exist among anxiety, cognitive avoidance, and binge eating.

Previously published research has shown a unique relation between avoidancebased coping and binge eating, after accounting for the role of negative affect (Spoor, Bekker, Van Strien, \& van Heck, 2007). However, findings from earlier studies have also suggested negative affect and limited self-awareness may operate independently in predicting binge eating (Engelberg et al., 2007). The data from the current study may be understood within the context of the above-mentioned findings, as these data suggest that anxiety may have a distinct role when examining cognitive avoidance in the context of negative affect and binge eating symptoms. The current data may also be interpreted within the context of previous research by Paxton and Diggens (1997) who found a relation between avoidance-based coping and binge eating, but did not find support for 
avoidance-based coping as a mediator. Of note, the current study is unique in its examination of cognitive avoidance and anxiety in relation to binge eating symptoms, as other cognitive avoidance research has focused on depression (Paxton \& Diggens, 1997) or negative affect, broadly (Blackburn et al., 2006). Overall, the data from the current study may be interpreted as partially supportive of the role of cognitive avoidance in the development and maintenance of binge eating.

Hostility and Binge Eating. In order to thoroughly examine various domains of negative affect in relation to binge eating, this study analyzed the correlation of hostility and binge eating symptomology. These data support a relation between hostility and binge eating. Further, they suggest that continued investigation of negative affect, inclusively conceptualized and operationalized, may expand the understanding of binge eating. Few investigations of negative affect and binge eating have focused on the role of hostility, however there is some support in the literature for hostility as an antecedent (Arnow, Kenardy, \& Agras, 1992; Stickney et al., 1999) and correlate (Kenardy, Arnow, \& Agras, 1996) of binge eating episodes. Some have suggested that hostility and other forms of negative affect that are most closely aligned with anger may be particular antecedents of binge eating following difficult interpersonal interactions with others, whereas other forms of negative affect may be more likely to serve as antecedents of binge eating following internal events (Kenardy et al., 1996). The data from the current study suggest that additional investigations regarding the specific role of hostility in relation to binge eating symptoms may be warranted.

Gender Differences and Implications. The current study found significantly higher levels of binge eating symptoms among women compared to men. To date, the 
literature has been mixed in regard to whether women (Kolotkin et al., 2004; Mitchell \& Mazzeo, 2004; Striegel-Moore et al., 2009) or men (Hudson et al., 2007) have higher rates of BED. Of note, women in the current study also reported higher levels of anxiety, stress, and hostility compared to men on these measures. Interestingly, there were no gender differences for depression. It is also noteworthy that there were no differences in income, employment, or level of education between men and women in this sample.

The co-occurrence of higher anxiety and higher binge eating symptoms among women may be best conceptualized as an expression of the cognitive avoidance theory of binge eating (Heatherton \& Baumeister, 1991), rather than a gender-specific phenomenon. That is, the higher reports of binge eating symptoms among women may be attributable to the higher levels of anxiety found among women in this sample. In line with this theory, women also reported higher levels of cognitive avoidance than men. It may be that women were more likely to engage in binge eating, through a process of cognitive avoidance, to "escape" from the difficult experience of anxiety. Therefore, it may be that binge eating would occur at a similar level across genders if anxiety and cognitive avoidance were also present at similar levels between men and women.

Men and women may face unique challenges of daily life. For instance, women may face different societal expectations in regard to body image than men. For this study, the similarities in socioeconomic status between genders in this sample suggest that perhaps gender-related societal factors might contribute to the increased prevalence of anxiety for women (e.g., the thin ideal, over-evaluation of shape and weight, perfectionism). This is supported by research that has linked body image concerns, 
gender-specific stress (such as sexual harassment), with greater eating pathology in women compared to men (Buchanan, Bluestein, Nappa, Woods, \& Depatie, 2013).

\section{Limitations}

While this study has strengths, including the geographically and ethnically diverse sample, it is not without limitations. First, although the study was well powered, it is notable that approximately $28 \%$ of individuals ( $n=123$ ) who responded with at least one piece of data and met the full inclusion criteria discontinued the survey without providing usable data on the main study outcome measures. Given that participants were offered the opportunity to enroll for one of seven $\$ 100$ gift card raffles at any point during survey completion, some participants who were primarily motivated by the raffle prize may have discontinued early.

Next, while the use of a web-based survey allowed for data collection across a broad geographic region and accommodated a large sample size, it did not allow for the use of clinician-administered interview measures. The use of such measures would reduce the influence of self-report bias and facilitate accurate diagnostic classification. Additional study using a smaller clinical sample may increase the feasibility of using interview measures, and allow for additional examination of negative affect within the context of BED.

Third, although this study was able to examine gender differences between men and women in regard to binge eating and domains of negative affect, examinations of transgendered individuals were not feasible given the small size of this subsample. Future research with targeted recruitment of transgendered individuals is needed to better understand negative affect and binge eating within this group. 
Fourth, this study was conducted using a cross-sectional design, contraindicating the examination of longitudinal or temporal relations. There are a variety of questions concerning negative affect and binge eating that the current study is not able to answer. That is, the directionality of relations between domains of negative affect, cognitive avoidance, and binge eating, cannot be examined through these data. In particular, future research utilizing repeated measures data collection over time may examine patterns in causality.

\section{Future Research and Clinical Implications}

The findings of the current study provide empirical support for theories of anxiety in binge eating behavior by demonstrating that anxiety has an independent association with binge eating symptoms; these results warrant continued research and replication. Future research may be important in further clarifying the nature of negative emotion and binge eating. Further, continued investigation, within the context of binge eating theory, may help to inform clinical care. Future research questions and clinical implications stemming from the current study are discussed in greater specificity below.

The current study examined the unique roles of various domains of negative emotionality in relation to binge eating symptoms. These data suggest that anxiety serves a unique role in relation to binge eating, beyond the contributions of depression. Differential relations are supported by these data; however, future research is needed to examine the extent to which these roles are expressed differentially over time. The predictive nature of the relation of anxiety and binge eating is not yet known. As such, studies examining differences in the relation of anxiety, depression, and binge eating over time are indicated. That is, future research is needed to examine whether anxiety and 
depression serve specific roles in regard to their temporal relations to binge eating (i.e., antecedent or consequence).

Future research with the ability to examine causality would greatly advance the understanding of anxiety and depression in relation to binge eating. Retrospective studies may be useful in assessing the longitudinal patterns of anxiety and depression in relation to binge eating. Reliance on participant recall may pose some potential complications; participants' emotional context and the temporal specificity of the recall period may present challenges to collecting accurate recollections. For instance, this method may necessitate more detailed retrieval if participants are asked to recall daily fluctuations in emotions over a period of several hours, rather than long-standing fluctuations over a period of weeks or months. Prospective studies and studies utilizing newer technology in their methodology may help to contribute to future predictive research to support the distinct temporal roles of anxiety and depression in binge eating.

The use of ecological momentary assessment has been used with success previously in binge eating research (Anestis et al., 2010; Haedt-Matt \& Keel, 2011; Munsch et al., 2009; Stein et al., 2007), and may facilitate clear examination of daily patterns of negative affect. Some have found that both anxiety and depression increase prior to a binge eating episode and decrease afterward within $\mathrm{BN}$, however the literature is generally inconsistent in understanding the temporal relation of specific domains of negative affect to binge eating (Berg et al., 2013). Indeed, at least one meta-analysis of ecological momentary assessment studies of binge eating suggests that while elevations in negative affect generally precede a binge eating episode, it does not necessarily decrease following the episode. The authors of this meta-analysis suggest that perhaps 
one-dimensional measurements of negative affect may fail to capture changes in specific domains of negative affect (Haedt-Matt \& Keel, 2011), supporting the notion that binge eating may serve to decrease one domain (i.e., anxiety), but contributes to increases in another (i.e., depression). Behavioral examinations, including functional analysis of binge eating may also contribute meaningfully to this end.

Furthermore, although a positive relation has been observed between anxiety and binge eating, additional research is needed in order to clarify whether there is a one-toone correspondence between these constructs. Particularly, future clinical trials may examine the extent to which the relation of anxiety to binge eating may differ based on clinically significant levels of each syndrome. It may be that a small increase in anxiety may correspond to a moderate to large exacerbation of binge eating symptoms. Additional examination of this question may better inform clinical intervention efforts.

The results of this study yield several clinical implications. First, these data suggest that intervention efforts for binge eating should be developed and adapted in consideration of the relation of negative affect to binge eating symptoms. Furthermore, a variety of domains of negative affect, including anxiety, stress, hostility, and depression, should be included in intervention development. It may be that targeted anxiety-specific intervention may be particularly effective in binge eating symptom reduction.

These findings also suggest that cognitive avoidance may play an important role in translating the experience of anxiety to the behavior of binge eating. Some have considered the ways in which binge eating may serve as a coping platform, albeit a maladaptive method, to mitigate the impact of difficult negative emotional experiences (Binford et al., 2004; Paxton \& Diggens, 1997; Troop, 1998). Effective binge eating 
interventions may specifically facilitate adoption and practice of adaptive coping methods.

The results of this study have implications for cognitive-behavioral interventions for binge eating. Cognitive-behavioral interventions have a strong record of utility in addressing binge eating symptoms (Brownley et al., 2007; Fairburn et al., 2009; Grilo, Masheb, \& Crosby, 2012). The efficacy of CBT for binge eating may be due in part to the way by which CBT prompts an examination of thoughts, and facilitates understanding of the connection between thoughts, emotion, and behavior.

Other interventions which mitigate the impact of cognitive avoidance may be useful supplements to CBT based on specific case formulation needs, and may be useful for cases in which traditional CBT may not produce sufficient gains. In particular, mindfulness based intervention techniques may be a useful method to draw awareness to intra-individual experience and intervene in the detrimental chain of events that follows cognitive avoidance prior to a binge eating episode. Indeed, some have shown that mindfulness tendencies are less common among individuals with BED compared to normal weight and non-BED obese individuals (Compare, Callus, \& Grossi, 2012). Some early research toward this end is promising, as highlighted by studies that have found mindfulness training is associated with a decrease in binge eating episodes (Courbasson, Nishikawa, \& Shapira, 2011; Dalen et al., 2010; Kristeller \& Wolever, 2011).

Acceptance-based interventions may also be a useful supplement for traditional CBT for BED. Increasing acceptance of negative emotions, particularly anxiety, may also mitigate binge eating symptoms by reducing reliance on cognitive avoidance. In addition, facilitation of acceptance of body image may also be an important component of 
maintaining treatment gains, as over-evaluation of shape and weight has been shown to be an important moderator of CBT treatment outcomes for individuals with BED (Grilo et al., 2012).

\section{Conclusion}

This study replicates and extends previous research that has found an association between negative affect and binge eating, broadly (Deaver et al., 2003; Schulz \& Laessle, 2010; Whiteside et al., 2007), and between specific factors such as anxiety (Ostrovsky et al., 2013) (Mitchell \& Mazzeo, 2004; Pinaquy et al., 2003; ReichbornKjennerud, Bulik, Tambs, \& Harris, 2004), depression (Araujo, Santos, \& Nardi, 2010; Azarbad et al., 2010; Mazzeo et al., 2006), and stress (Freeman \& Gil, 2004; Sulkowski et al., 2011). Taken in this context, the current study compliments and broadens the understanding of the relation of negative affect and binge eating already identified in the literature. This study has identified strong relations between a variety of domains of negative emotionality and binge eating, including depression, anxiety, stress, and hostility. This study also supports the role of cognitive avoidance as a partial mediator of the relation between anxiety and binge eating. In sum, this study supports the role of anxiety as a primary factor in the relation of negative affect and binge eating, superseding the role of depression. 


\section{References}

Abbott, D. W., de Zwaan, M., Mussell, M. P., Raymond, N. C., Seim, H. C., Crow, S. J., et al. (1998). Onset of binge eating and dieting in overweight women: implications for etiology, associated features and treatment. Journal of psychosomatic research, 44, 367-374.

Allen, M. P. (1997). The problem of multicollinearity Understanding Regression Analysis (pp. 176-181). New York: Springer.

American Psychiatric Assocation. (2000). Diagnostic and statistical manual of mental disorders: DSM-IV-TR. Washington, DC: American Psychiatric Association.

American Psychiatric Assocation. (2013). Diagnostic and statistical manual of mental disorders, fifth edition (DSM-5). Arlington, VA: American Psychiatric Association.

Anestis, M. D., Selby, E. A., Crosby, R. D., Wonderlich, S. A., Engel, S. G., \& Joiner, T. E. (2010). A comparison of retrospective self-report versus ecological momentary assessment measures of affective lability in the examination of its relationship with bulimic symptomatology. Behaviour Research and Therapy, 48, 607-613. doi: 10.1016/j.brat.2010.03.012

Antony, M. M., Bieling, P. J., Cox, B. J., Enns, M. W., \& Swinson, R. P. (1998). Psychometric properties of the 42-item and 21-item versions of the Depression Anxiety Stress Scales in clinical groups and a community sample. Psychological Assessment, 10, 176-181.

Araujo, D. M. R., Santos, G. F. D. S., \& Nardi, A. E. (2010). Binge eating disorder and depression: A systematic review. World Journal of Biological Psychiatry(2 PART 2), 199-207. doi: 10.3109/15622970802563171

Arnow, B., Kenardy, J., \& Agras, W. S. (1992). Binge eating among the obese: A descriptive study. Journal of Behavioral Medicine, 15, 155-170.

Azarbad, L., Corsica, J., Hall, B., \& Hood, M. (2010). Psychosocial correlates of binge eating in Hispanic, African American, and Caucasian women presenting for bariatric surgery. Eating Behaviors, 11, 79-84. doi: 10.1016/j.eatbeh.2009.10.001

Baron, R. M., \& Kenny, D. A. (1986). The moderator-mediator variable distinction in social psychological research: Conceptual, strategic, and statistical considerations. Journal of Personality and Social Psychology, 51, 1173-1182.

Berg, K. C., Crosby, R. D., Cao, L., Peterson, C. B., Engel, S. G., Mitchell, J. E., et al. (2013). Facets of negative affect prior to and following binge-only, purge-only, and binge/purge events in women with bulimia nervosa. Journal of Abnormal Psychology, 122(1), 111-118. doi: 10.1037/a0029703

Bergdahl, J., \& Bergdahl, M. (2002). Perceived stress in adults: prevalence and association of depression, anxiety and medication in a Swedish population. Stress and Health, 18, 235-241.

Binford, R. B., Mussell, M. P., Peterson, C. B., Crow, S. J., \& Mitchell, J. E. (2004). Relation of binge eating age of onset to functional aspects of binge eating in binge eating disorder. International Journal of Eating Disorders, 35, 286-292. doi: 10.1002/eat. 10272 
Blackburn, S., Johnston, L., Blampied, N., Popp, D., \& Kallen, R. (2006). An application of escape theory to binge eating. European Eating Disorders Review, 14(1), 2331. doi: 10.1002/erv.675

Brown, T. A., Chorpita, B. F., \& Barlow, D. H. (1998). Structural relationships among dimensions of the DSM-IV anxiety and mood disorders and dimensions of negative affect, positive affect, and autonomic arousal. Journal of Abnormal Psychology, 107(2), 179-192. doi: 10.1037/0021-843X.107.2.179

Brownley, K. A., Berkman, N. D., Sedway, J. A., Lohr, K. N., \& Bulik, C. M. (2007). Binge eating disorder treatment: A systematic review of randomized controlled trials. International Journal of Eating Disorders, 40, 337-348. doi: 10.1002/eat.20370

Bruce, B., \& Agras, W. S. (1992). Binge eating in females: A population-based investigation. International Journal of Eating Disorders, 12, 365-373.

Buchanan, N. T., Bluestein, B. M., Nappa, A. C., Woods, K. C., \& Depatie, M. M. (2013). Exploring gender differences in body image, eating pathology, and sexual harassment. Body Image.

Bulik, C. M., Sullivan, P. F., \& Kendler, K. S. (2002). Medical and psychiatric morbidity in obese women with and without binge eating. International Journal of Eating Disorders, 32, 72-78. doi: 10.1002/eat.10072

Centers for Disease Control and Prevention. (2012). Health, United States, 2011: With Special Feature on Socioeconomic Status and Health. Hyattsville, MD: National Center for Health Statistics Retrieved from http://www.cdc.gov/nchs/.

Clark, L. A., \& Watson, D. (1991). Tripartite model of anxiety and depression: Psychometric evidence and taxonomic implications. Journal of Abnormal Psychology, 100, 316-336.

Cohen, S., \& Janicki-Deverts, D. (2012). Who's stressed? Distributions of psychological stress in the United States in probability samples from 1983, 2006, and 2009. Journal of Applied Social Psychology, 42(6), 1320-1334. doi: 10.1111/j.15591816.2012.00900.x

Cohen, S., Kamarck, T., \& Mermelstein, R. (1983). A global measure of perceived stress. Journal of Health and Social Behavior, 24, 385-396.

Compare, A., Callus, E., \& Grossi, E. (2012). Mindfulness trait, eating behaviours and body uneasiness: A case-control study of binge eating disorder. Eating and Weight Disorders, 17(4), e244-e251.

Courbasson, C. M., Nishikawa, Y., \& Shapira, L. B. (2011). Mindfulness-action based cognitive behavioral therapy for concurrent binge eating disorder and substance use disorders. Eating Disorders, 19(1), 17-33.

Craske, M. G., Rauch, S. L., Ursano, R., Prenoveau, J., Pine, D. S., \& Zinbarg, R. E. (2009). What is an anxiety disorder? Depression and Anxiety, 26(12), 1066-1085. doi: 10.1002/da.20633

Crowther, J. H., Sanftner, J., Bonifazi, D. Z., \& Shepherd, K. L. (2001). The role of daily hassles in binge eating. International Journal of Eating Disorders, 29(4), 449454. doi: 10.1002/eat.1041

Dalen, J., Smith, B. W., Shelley, B. M., Sloan, A. L., Leahigh, L., \& Begay, D. (2010). Pilot study: Mindful Eating and Living (MEAL): Weight, eating behavior, and psychological outcomes associated with a mindfulness-based intervention for 
people with obesity. Complementary Therapies in Medicine, 18(6), 260-264. doi: http://dx.doi.org/10.1016/j.ctim.2010.09.008

Darby, A., Hay, P., Mond, J., Rodgers, B., \& Owen, C. (2007). Disordered eating behaviors and cognitions in young women with obesity: Relationship with psychological status. International Journal of Obesity, 31, 876-882. doi: 10.1038/sj.ijo.0803501

De Zwaan, M., Mitchell, J. E., Michael Howell, L., Monson, N., Swan-Kremeier, L., Crosby, R. D., et al. (2003). Characteristics of morbidly obese patients before gastric bypass surgery. Comprehensive Psychiatry, 44(5), 428-434. doi: 10.1016/S0010-440X(03)00092-0

Deaver, C. M., Miltenberger, R. G., Smyth, J., Meidinger, A., \& Crosby, R. (2003). An evaluation of affect and binge eating. Behavior Modification, 27(4), 578-599. doi: 10.1177/0145445503255571

Dingemans, A. E., Martijn, C., Jansen, A. T., \& van Furth, E. F. (2009). The effect of suppressing negative emotions on eating behavior in binge eating disorder. Appetite, 52, 51-57. doi: 10.1016/j.appet.2008.08.004

Dunn, E. C., Neighbors, C., \& Larimer, M. (2003). Assessing readiness to change binge eating and compensatory behaviors. Eating Behaviors, 4(3), 305-314. doi: 10.1016/S1471-0153(03)00023-0

Engelberg, M. J., Steiger, H., Gauvin, L., \& Wonderlich, S. A. (2007). Binge antecedents in bulimic syndromes: An examination of dissociation and negative affect. International Journal of Eating Disorders, 40(6), 531-536. doi: 10.1002/eat.20399

Fairburn, C. G. (2008). Eating disorders: the transdiagnostic view and the cognitive behavioral theory. In C. G. Fairburn (Ed.), Cognitive behavior therapy and eating disorders (pp. 7-22). New York: Guilford Press.

Fairburn, C. G., Cooper, Z., \& Cooper, P. J. (1986). The clinical features and maintenance of bulimia nervosa. In K. D. Brownell \& J. P. Foreyt (Eds.), Handbook of eating disorders: Physiology, psychology and treatment of obesity, anorexia and bulimia (pp. 389-404). New York: Basic Books.

Fairburn, C. G., Cooper, Z., Doll, H. A., O'Connor, M. E., Bohn, K., Hawker, D. M., et al. (2009). Transdiagnostic Cognitive-Behavioral therapy for patients with eating disorders: A two-site trial with 60-week follow-up. American Journal of Psychiatry, 166(3), 311-319. doi: 10.1176/appi.ajp.2008.08040608

Fairburn, C. G., Cooper, Z., \& Shafran, R. (2003). Cognitive behavior therapy for eating disorders: A "transdiagnostic" theory and treatment. Behavior Research and Therapy, 41, 509-528. doi: 10.1016/S0005-7967(02)00088-8

Feigelson, M. E., \& Dwight, S. A. (2000). Can Asking Questions by Computer Improve the Candidness of Responding? A Meta-Analytic Perspective. Consulting Psychology Journal, 52(4), 248-255. doi: 10.1037/1061-4087.52.4.248

Fichter, M. M., Quadflieg, N., \& Hedlund, S. (2008). Long-term course of binge eating disorder and bulimia nervosa: Relevance for nosology and diagnostic criteria. International Journal of Eating Disorders, 41, 577-586. doi: 10.1002/eat.20539

Freeman, L. M. Y., \& Gil, K. M. (2004). Daily stress, coping, and dietary restraint in binge eating. International Journal of Eating Disorders, 36(2), 204-212. doi: 10.1002/eat.20012 
Gautier, J. F., Del Parigi, A., Chen, K., Salbe, A. D., Bandy, D., Pratley, R. E., et al. (2001). Effect of satiation on brain activity in obese and lean women. Obesity Research, 9, 676-684. doi: 10.1038/oby.2001.92

Gluck, M. E. (2006). Stress response and binge eating disorder. Appetite, 46, 26-30. doi: 10.1016/j.appet.2005.05.004

Godart, N. T., Flament, M. F., Curt, F., Perdereau, F., Lang, F., Venisse J.L., et al. (2003). Anxiety disorders in subjects seeking treatment for eating disorders: A DSM-IV controlled study. Psychiatry Research, 117, 245-258. doi: 10.1016/S0165-1781(03)00038-6

Goldschmidt, A. B., Engel, S. G., Wonderlich, S. A., Crosby, R. D., Peterson, C. B., Le Grange, D., et al. (2012). Momentary affect surrounding loss of control and overeating in obese adults with and without binge eating disorder. Obesity, 20(6), 1206-1211. doi: 10.1038/oby.2011.286

Greeno, C. G., Wing, R. R., \& Shiffman, S. (2000). Binge antecedents in obese women with and without binge eating disorder. Journal of Consulting and Clinical Psychology, 68(1), 95-102.

Grilo, C. M. (2002). Binge eating disorder. In C. G. Fairburn \& K. D. Brownell (Eds.), Eating Disorders and Obesity: A Comprehensive Handbook, 2nd edition (pp. 178-182). New York: Guilford Press.

Grilo, C. M., Masheb, R. M., \& Crosby, R. D. (2012). Predictors and moderators of response to cognitive behavioral therapy and medication for the treatment of binge eating disorder. Journal of Consulting and Clinical Psychology, 80(5), 897906. doi: 10.1037/a0027001

Grilo, C. M., \& Shiffman, S. (1994). Longitudinal investigation of the abstinence violation effect in binge eaters. Journal of Consulting and Clinical Psychology, 62, 611-619. doi: 10.1037/0022-006X.62.3.611

Grilo, C. M., White, M. A., Barnes, R. D., \& Masheb, R. M. (2013). Psychiatric disorder co-morbidity and correlates in an ethnically diverse sample of obese patients with binge eating disorder in primary care settings. Comprehensive Psychiatry, 54(3), 209-216. doi: http://dx.doi.org/10.1016/j.comppsych.2012.07.012

Grilo, C. M., White, M. A., \& Masheb, R. M. (2009). DSM-IV psychiatric disorder comborbidity and its correlates in binge eating disorder. International Journal of Eating Disorders, 42, 228-234. doi: 10.1002/eat.20599

Grucza, R. A., Przybeck, T. R., \& Cloninger, C. R. (2007). Prevalence and correlates of binge eating disorder in a community sample. Comprehensive Psychiatry, 48, 124-131. doi: 10.1016/j.comppsych.2006.08.002

Guerdjikova, A. I., McElroy, S. L., Kotwal, R., \& Keck, P. E. (2007). Comparison of obese men and women with binge eating disorder seeking weight management. Eating and Weight Disorders, 12, e19-e23.

Haedt-Matt, A. A., \& Keel, P. K. (2011). Revisiting the affect regulation model of binge eating: A meta-analysis of studies using ecological momentary assessment. Psychological Bulletin, 137(4), 660-681.

Hayes, S. C., Strosahl, K., Wilson, K. G., Bisset, R. T., Pistorello, J., Toarmino, D., et al. (2004). Measuring experiential avoidance: A preliminary test of a working model. The Psychological Record(54), 553-578. 
Heatherton, T. F., \& Baumeister, R. F. (1991). Binge eating as escape from selfawareness. Psychological Bulletin, 110, 86-108. doi: 10.1037//00332909.110.1.86

Henry, J. D., \& Crawford, J. R. (2005). The short-form version of the Depression Anxiety Stress Scales (DASS-21): Construct validity and normative data in a large nonclinical sample. British Journal of Clinical Psychology, 44, 227-239. doi: 10.1348/014466505X29657

Hudson, J. I., Hiripi, E., Pope Jr, H. G., \& Kessler, R. C. (2007). The prevalence and correlates of eating disorders in the national comorbidity survey replication. Biological Psychiatry, 61(3), 348-358. doi: 10.1016/j.biopsych.2006.03.040

Hutcheson, G., \& Sofroniou, N. (1999). The multivariate social scientist: Introductory statistics using generalized linear models. Thousand Oakes, CA: Sage.

Javaras, K. N., Pope Jr., H. G., Lalonde, J. K., Roberts, J. L., Nillni, Y. I., Laird, N. M., et al. (2008). Co-occurrence of binge eating disorder with psychiatric and medical disorders. Journal of Clinical Psychiatry, 69, 266-273.

Kashubeck-West, S., Mintz, L. B., \& Weigold, I. (2005). Separating the effects of gender and weight-loss desire on body satisfaction and disordered eating behavior. Sex Roles, 53, 505-518. doi: 10.1007/s11199-005-7138-4

Kaye, W. H., Gwirtsman, H. E., George, D. T., Weiss, S. R., \& Jimerson, D. C. (1986). Relationship of mood alterations to bingeing behaviour in bulimia. The British Journal of Psychiatry, 149(4), 479-485. doi: 10.1192/bjp.149.4.479

Kenardy, J., Arnow, B., \& Agras, W. S. (1996). The aversiveness of specific emotional states associated with binge-eating in obese subjects. Australian and New Zealand Journal of Psychiatry, 30(6), 839-844.

Kolotkin, R., Westman, E., Ostby, T., Crosby, R. D., Eisenson, H., \& Binks, M. (2004). Does binge eating disorder impact weight-related quality of life? Obesity, 12, 999-1005. doi: 10.1038/oby.2004.122

Kristeller, J. L., \& Wolever, R. Q. (2011). Mindfulness-based eating awareness training for treating binge eating disorder: The conceptual foundation. Eating Disorders, 19(1), 49-61.

Laessle, R. G., \& Schulz, S. (2009). Stress-induced laboratory eating behavior in obese women with binge eating disorder. International Journal of Eating Disorders, 42(6), 505-510. doi: 10.1002/eat.20648

Lamarche, L., \& Gammage, K. L. (2012). Predicting exercise and eating behaviors from appearance evaluation and two types of investment. Sport, Exercise, and Performance Psychology, 3(1), 145-157. doi: 10.1037/a0026892

Lee, E.-H. (2012). Review of the psychometric evidence of the perceived stress scale. Asian Nursing Research, 6(4), 121-127. doi: http://dx.doi.org/10.1016/j.anr.2012.08.004

Lewinsohn, P. M., Seeley, J. R., Moerk, K. C., \& Striegel-Moore, R. H. (2002). Gender differences in eating disorder symptoms in young adults. International Journal of Eating Disorders, 32(4), 426-440. doi: 10.1002/eat.10103

Lilenfeld, L. R. R., Ringham, R., Kalarchian, M. A., \& Marcus, M. D. (2008). A family history study of binge-eating disorder. Comprehensive Psychiatry, 49, 247-254. doi: 10.1016/j.comppsych.2007.10.001 
Lingswiler, V. M., Crowther, J. H., \& Stephens, M. A. P. (1989). Affective and cognitive antecedents to eating episodes in bulimia and binge eating. International Journal of Eating Disorders, 8, 533-539. doi: 10.1002/1098108X(198909)8:5<533::AID-EAT2260080505>3.0.CO;2-O

Loth, K., van den Berg, P., Eisenberg, M. E., \& Neumark-Sztainer, D. (2008). Stressful life events and disordered eating behaviors: Findings from Project EAT. Journal of Adolescent Health, 43, 514-516. doi: 10.1016/j.adohealth.2008.03.007

Lovibond, P. F., \& Lovibond, S. H. (1995a). Manual for the Depression Anxiety Stress Scales. Sydney, Australia: Psychology Foundation of Australia.

Lynch, F. L., Striegel-Moore, R. H., Dickerson, J. F., Perrin, N., DeBar, L., Wilson, G. T., et al. (2010). Cost-effectiveness of guided self-help treatment for recurrent binge eating. Journal of Consulting and Clinical Psychology, 78, 322-333. doi: 10.1037/a0018982

Marcus, M. D., Bromberger, J. T., Wei, H. L., Brown, C., \& Kravitz, H. M. (2007). Prevalence and selected correlates of eating disorder symptoms among a multiethnic community sample of midlife women. Annals of Behavioral Medicine, 33(3), 269-277. doi: 10.1007/BF02879909

Mazzeo, S. E., Saunders, R., \& Mitchell, K. S. (2005). Binge eating among African American and Caucasian bariatric surgery candidates. Eating Behaviors, 6, 189196. doi: 10.1016/j.eatbeh.2004.12.001

Mazzeo, S. E., Saunders, R., \& Mitchell, K. S. (2006). Gender and binge eating among bariatric surgery candidates. Eating Behaviors, 7, 47-52. doi: 10.1016/j.eatbeh.2005.05.008

McDowell, I. (2006). Measuring Health: A Guide to Rating Scales and Questionnaires (Third ed.). New York: Oxford University Press.

McLaren, S., \& Crowe, S. F. (2003). The contribution of perceived control of stressful life events and thought suppression to the symptoms of obsessive-compulsive disorder in both non-clinical and clinical samples. Anxiety Disorders, 17, 389403.

Meyer, C., Serpell, L., Waller, G., Murphy, F., Treasure, J., \& Leung, N. (2005).

Cognitive avoidance in the strategic processing of ego threats among eatingdisordered patients. International Journal of Eating Disorders, 38(1), 30-36. doi: 10.1002/eat.20147

Mitchell, J. E., Mussell, M. P., Peterson, C. B., Crow, S., Wonderlich, S. A., Crosby, R. D., et al. (1999). Hedonics of binge eating in women with bulimia nervosa and binge eating disorder. International Journal of Eating Disorders, 26, 165-170. doi: 10.1002/(SICI)1098-108X(199909)26:2<165::AID-EAT5>3.3.CO;2-8

Mitchell, K. S., \& Mazzeo, S. E. (2004). Binge eating and psychological distress in ethnically diverse undergraduate men and women. Eating Behaviors, 5, 157-169. doi: 10.1016/j.eatbeh.2003.07.004

Munsch, S., Meyer, A. H., Milenkovic, N., Schlup, B., Margraf, J., \& Wilhelm, F. H. (2009). Ecological momentary assessment to evaluate cognitive-behavioral treatment for binge eating disorder. International Journal of Eating Disorders, 42, 648-657. doi: 10.1002/eat.20657 
Mussell, M. P., Mitchell, J. E., De Zwaan, M., Crosby, R. D., Seim, H. C., \& Crow, S. J. (1996). Clinical characteristics associated with binge eating in obese females: A descriptive study. International Journal of Obesity, 20(4), 324-331.

Napolitano, M. A., \& Himes, S. (2011). Race, weight, and correlates of binge eating in female college students. Eating Behaviors, 12, 29-36. doi: 10.1016/j.eatbeh.2010.09.003

Osman, A., Wong, J. L., Bagge, C. L., Freedenthal, S., Gutierrez, P. M., \& Lozano, G. (2012). The depression anxiety stress scales-21 (DASS-21): Further examination of dimensions, scale reliability, and correlates. Journal of Clinical Psychology, 68(12), 1322-1338. doi: 10.1002/jclp.21908

Ostrovsky, N. W., Swencionis, C., Wylie-Rosett, J., \& Isasi, C. R. (2013). Social anxiety and disordered overeating: An association among overweight and obese individuals. Eating Behaviors, 14(2), 145-148. doi: http://dx.doi.org/10.1016/j.eatbeh.2013.01.009

Pallister, E., \& Waller, G. (2008). Anxiety in the eating disorders: Understanding the overlap. Clinical Psychology Review, 28, 366-386. doi: 10.1016/j.cpr.2007.07.001

Paxton, S. J., \& Diggens, J. (1997). Avoidance coping, binge eating, and depression: An examination of the Escape Theory of binge eating. International Journal of Eating Disorders, 22.

Pinaquy, S., Chabrol, H., Simon, C., Louvet, J. P., \& Barbe, P. (2003). Emotional eating, alexithymia, and binge-eating disorder in obese women. Obesity Research, 11, 195-201.

Pokrajac-Bulian, A., Tkalčić, M., \& Ambrosi-Randić, N. (2013). Binge eating as a determinant of emotional state in overweight and obese males with cardiovascular disease. Maturitas, 74(4), 352-356. doi: http://dx.doi.org/10.1016/j.maturitas.2013.01.007

Pollert, G. A., Engel, S. G., Schreiber-Gregory, D. N., Crosby, R. D., Cao, L., Wonderlich, S. A., et al. (2013). The role of eating and emotion in binge eating disorder and loss of control eating. International Journal of Eating Disorders, 46, 233-238. doi: 10.1002/eat.22061

Rapee, R. M., Craske, M. G., Brown, T. A., \& Barlow, D. H. (1996). Measurement of perceived control over anxiety-related events. Behavior Therapy, 27, 279-293.

Reichborn-Kjennerud, T., Bulik, C. M., Sullivan, P. F., Tambs, K., \& Harris, J. R. (2004). Psychiatric and medical symptoms in binge eating in the absence of compensatory behaviors. Obesity Research, 12(9), 1445-1454. doi: 10.1038/oby.2004.181

Reichborn-Kjennerud, T., Bulik, C. M., Tambs, K., \& Harris, J. R. (2004). Genetic and environmental influences on binge eating in the absence of compensatory behaviors: A population-based twin study. International Journal of Eating Disorders, 36, 307-314. doi: 10.1002/eat.20047

Rosenberg, N., Bloch, M., Ben Avi, I., Rouach, V., Schreiber, S., Stern, N., et al. (in press). Cortisol response and desire to binge following psychological stress: Comparison between obese subjects with and without binge eating disorder. Psychiatry Research(0). doi: http://dx.doi.org/10.1016/j.psychres.2012.09.050

Sanderson, W. C., Rapee, R. M., \& Barlow, D. H. (1989). The influence of an illusion of control on panic attacks induced via inhalation of $5.5 \%$ carbon-dioxide-enriched air. Archives of General Psychiatry, 46, 157-162. 
Schulz, S., \& Laessle, R. G. (2010). Associations of negative affect and eating behaviour in obese women with and without binge eating disorder. Eating and Weight Disorders, 15(4), 287-293.

Shaw, H., Ramirez, L., Trost, A., Randall, P., \& Stice, E. (2004). Body image and eating disturbances across ethnic groups: More similarities than differences. Psychology of Addictive Behaviors, 18, 12-18. doi: 10.1037/0893-164X.18.1.12

Sherry, S. B., \& Hall, P. A. (2009). The perfectionism model of binge eating: Tests of an integrative model. Journal of Personality and Social Psychology, 96, 690-709. doi: $10.1037 / \mathrm{a} 0014528$

Sierra-Baigrie, S., Lemos-Giráldez, S., Paino, M., \& Fonseca-Pedrero, E. (2012). Exploring the relationship between coping strategies and binge eating in nonclinical adolescents. European Eating Disorders Review, 20(1), e63-e69.

Smith, D. E., Marcus, M. D., Lewis, C. E., Fitzgibbon, M., \& Schreiner, P. (1998). Prevalence of binge eating disorder, obesity, and depression in a biracial cohort of young adults. Annals of Behavioral Medicine, 20, 227-232. doi: 10.1007/BF02884965

Spindler, A., \& Milos, G. (2007). Links between eating disorder symptom severity and psychiatric comorbidity. Eating Behaviors, 8, 364-373. doi:

10.1016/j.eatbeh.2006.11.012

Spitzer, R. L., Devlin, M., Walsh, B. T., Hasin, D., Wing, R., Marcus, M., et al. (1992). Binge eating disorder: A multisite field trial of the diagnostic criteria. International Journal of Eating Disorders, 11, 191-203. doi: 10.1002/1098108X(199204)11:3<191::AID-EAT2260110302>3.0.CO;2-S

Spitzer, R. L., Yanovski, S., Wadden, T., Wing, R., Marcus, M. D., Stunkard, A., et al. (1993). Binge eating disorder: Its further validation in a multisite study. International Journal of Eating Disorders, 13, 137-153.

Spoor, S. T. P., Bekker, M. H. J., Van Strien, T., \& van Heck, G. L. (2007). Relations between negative affect, coping, and emotional eating. Appetite, 48(3), 368-376.

SPSS. (2006). SPSS for Windows. Chicago: SPSS Inc.

Stein, R. I., Kenardy, J., Wiseman, C. V., Dounchis, J. Z., Arnow, B. A., \& Wilfley, D. E. (2007). What's driving the binge in binge eating disorder?: A prospective examination of precursors and consequences. International Journal of Eating Disorders, 40, 195-203. doi: 10.1002/eat.20352

Stice, E., Fisher, M., \& Martinez, E. (2004). Eating disorder diagnostic scale: Additional evidence of reliability and validity. Psychological Assessment, 16(1), 60-71. doi: 10.1037/1040-3590.16.1.60

Stice, E., Presnell, K., \& Spangler, D. (2002). Risk factors for binge eating onset in adolescent girls: A 2-year prospective investigation. Health Psychology, 21(2), 131-138.

Stice, E., \& Ragan, J. (2002). A preliminary controlled evaluation of an eating disturbance psychoeducational intervention for college students. International Journal of Eating Disorders, 31(2), 159-171. doi: 10.1002/eat.10018

Stice, E., Telch, C. F., \& Rizvi, S. L. (2000). Development and validation of the eating disorder diagnostic scale: A brief self-report measure of anorexia, bulimia, and binge-eating disorder. Psychological Assessment, 12, 123-131. doi: 10.1037//1040-3590.12.2.123 
Stickney, M. I., Miltenberger, R. G., \& Wolff, G. (1999). A descriptive analysis of factors contributing to binge eating. Journal of Behavior Therapy and Experimental Psychiatry, 30(3), 177-189. doi: 10.1016/S0005-7916(99)00019-1

Striegel-Moore, R. H., \& Bulik, C. M. (2007). Risk factors for eating disorders. American Psychologist, 62, 181-198. doi: 10.1037/0003-066X.62.3.181

Striegel-Moore, R. H., Rosselli, F., Perrin, N., DeBar, L., Wilson, G. T., May, A., et al. (2009). Gender difference in the prevalence of eating disorder symptoms. International Journal of Eating Disorders, 42, 471-474. doi: 10.1002/eat.20625

Striegel-Moore, R. H., Wilfley, D., Pike, K. M., Dohm, F., \& Fairburn, C. G. (2000). Recurrent binge eating in black American women. Archives of Family Medicine, 9, 83-87. doi: 10.1001/archfami.9.1.83

Sulkowski, M. L., Dempsey, J., \& Dempsey, A. G. (2011). Effects of stress and coping on binge eating in female college students. Eating Behaviors, 12(3), 188-191. doi: 10.1016/j.eatbeh.2011.04.006

Tanofsky-Kraff, M., Shomaker, L. B., Olsen, C., Roza, C. A., Wolkoff, L. E., Columbo, K. M., et al. (2011). A prospective study of pediatric loss of control eating and psychological outcomes. Journal of Abnormal Psychology, 120, 108-118. doi: $10.1037 / \mathrm{a} 0021406$

Taylor, J. Y., Caldwell, C. H., Baser, R. E., Faison, N., \& Jackson, J. S. (2007). Prevalence of eating disorders among blacks in the National Survey of American Life. International Journal of Eating Disorders, 40. doi: 10.1002/eat.20451

Telch, C. F., \& Stice, E. (1998). Psychiatric comorbidity in women with binge eating disorder: Prevalence rates from a non-treatment-seeking sample. Journal of Consulting and Clinical Psychology, 66, 768-776. doi: 10.1037/0022006X.66.5.768

Torres, S. J., \& Nowson, C. A. (2007). Relationship between stress, eating behavior, and obesity. Nutrition, 23(11-12), 887-894. doi: 10.1016/j.nut.2007.08.008

Troop, N. A. (1998). Eating disorders as coping strategies: A critique. European Eating Disorders Review, 6, 229-237.

U.S. Census Bureau. Census 2000 Summary File 1. Retrieved from http://factfinder.census.gov.

Watson, D., \& Clark, L. A. (1994). The PANAS-X: Manual for the positive and negative affect schedule-Expanded Form. Iowa City: University of Iowa.

Wegner, D. M., \& Zanakos, S. (1994). Chronic thought suppression. Journal of Personality, 62(615-640).

Whiteside, U., Chen, E., Neighbors, C., Hunter, D., Lo, T., \& Larimer, M. (2007). Difficulties regulating emotions: Do binge eaters have fewer strategies to modulate and tolerate negative affect? Eating Behaviors, 8(2), 162-169. doi: 10.1016/j.eatbeh.2006.04.001

Wilfley, D. E., Friedman, M. A., Dounchis, J. Z., Stein, R. I., Robinson Welch, R., \& Ball, S. A. (2000). Comorbid psychopathology in binge eating disorder: Relation to eating disorder severity at baseline and following treatment. Journal of Consulting and Clinical Psychology, 68(4), 641-649. doi: 10.1037/0022006X.68.4.641 
Woods, A. M., Racine, S. E., \& Klump, K. L. (2010). Examining the relationship between dietary restraint and binge eating: Differential effects of major and minor stressors. Eating Behaviors, 11(4), 276-280. doi: 10.1016/j.eatbeh.2010.08.001

Yanovski, S. Z., Nelson, J. E., Dubbert, B. K., \& Spitzer, R. L. (1993). Association of binge eating disorder and psychiatric comorbidity in obese subjects. American Journal of Psychiatry, 150(10), 1472-1479.

York, R. (2012). Residualization is not the answer: Rethinking how to address multicollinearity. Social Science Research, 41(6), 1379-1386. doi: http://dx.doi.org/10.1016/j.ssresearch.2012.05.014 
Table 1

Participant Characteristics

\begin{tabular}{lll}
\hline Demographic Variable & $\begin{array}{l}\text { Frequency } \\
(N=436)\end{array}$ & Percentage* \\
\hline Race/Ethnicity & 278 & 64.7 \\
White & 65 & 15.1 \\
Black or African American & 32 & 7.4 \\
Asian American & 28 & 6.5 \\
Hispanic or Latino & 21 & 4.9 \\
Biracial or Multiracial & 5 & 1.2 \\
American Indian or Alaska Native & 1 & 0.2 \\
Native Hawaiian or Pacific Islander & 6 & -- \\
Missing/Not Reported & & 34.7 \\
U.S. Region & 146 & 19.0 \\
Midwest & 80 & 16.4 \\
East Coast/Mid-Atlantic & 69 & 15.7 \\
South/Southeast & 66 & 8.3 \\
West Coast/Pacific Northwest & 35 & 5.7 \\
Southwest & 24 & 0.2 \\
New England & 1 & -- \\
Alaska or Hawaii & 15 & \\
Missing/Not Reported & & 42 \\
Urban/Metropolitan & 174 & 47 \\
Suburban & 195 & 10.8 \\
Rural/Small Town & 45 & 0.2 \\
Other & 1 & -- \\
Missing/Not Reported & 21 & \\
\hline
\end{tabular}

* Note. Percentages are calculated based on total reported data and are not inclusive of missing/not reported data. 
Table 2

Self-Reported History of Psychological and Medical Diagnoses

\begin{tabular}{llc}
\hline Diagnosis & $\begin{array}{c}\text { Past or Current } \\
\text { Diagnosis (\%) }\end{array}$ & $\begin{array}{c}\text { Currently } \\
\text { Treated (\%) }\end{array}$ \\
\hline $\begin{array}{c}\text { Psychological Diagnosis } \\
\text { Major Depressive Disorder }\end{array}$ & 19.4 & 12.4 \\
Dysthymia & 1.8 & 1.3 \\
Bipolar Disorder I & 4.1 & 1.3 \\
Bipolar Disorder II & 1.5 & 1.0 \\
Cyclothymia & 0.3 & 0.3 \\
Mood Disorder NOS & 4.3 & 2.8 \\
& & 3.1 \\
Panic Disorder & 5.9 & 0.3 \\
Agoraphobia (without Panic Disorder) & 0.5 & 0.8 \\
Specific Phobia & 5.4 & 4.8 \\
Social Anxiety Disorder & 7.0 & 8.1 \\
Generalized Anxiety Disorder & 13.0 & 5.1 \\
Anxiety Disorder NOS & 7.2 & \\
& & 13.8 \\
Medical Diagnosis & & 7.6 \\
Overweight or Obesity & 31.8 & 13.5 \\
Type 2 Diabetes & 6.9 & 11.1 \\
Hypertension & 19 & \\
Hyperlipidemia & 19.2 & \\
& &
\end{tabular}


PSYCHOLOGICAL FACTORS AND BINGE EATING

Table 3

Means and Standard Deviations for Key Variables $(N=313)$

\begin{tabular}{|c|c|c|c|c|c|c|c|c|}
\hline & \multicolumn{2}{|c|}{ Full Sample } & \multicolumn{2}{|c|}{ Women } & \multicolumn{2}{|c|}{ Men } & \multirow[b]{2}{*}{$t$} & \multirow[b]{2}{*}{$p$} \\
\hline & Mean & S.D. & Mean & S.D. & Mean & S.D. & & \\
\hline Depression (DASS) & 10.91 & 11.3 & 11.27 & 10.73 & 11.2 & 11.68 & -0.06 & 0.95 \\
\hline Anxiety (DASS) & 7.56 & 8.15 & 8.79 & 8.56 & 6.64 & 7.58 & -2.41 & 0.02 \\
\hline Perceived Stress (PSS) & 18.33 & 8.46 & 19.58 & 8.01 & 16.81 & 8.9 & -2.97 & 0.00 \\
\hline $\begin{array}{l}\text { Hostility } \\
\text { (H-PANAX-X) }\end{array}$ & 13.30 & 5.74 & 13.80 & 5.48 & 12.15 & 5.87 & -2.33 & 0.02 \\
\hline $\begin{array}{l}\text { Cognitive Avoidance } \\
\text { (WBSI) }\end{array}$ & 47.52 & 16.28 & 50.06 & 15.06 & 42.62 & 17.56 & -3.43 & 0.00 \\
\hline $\begin{array}{l}\text { Binge Eating } \\
\text { Symptoms } \\
\text { (EDDS) }\end{array}$ & 7.82 & 5.72 & 8.33 & 5.78 & 7.02 & 5.59 & -1.95 & 0.05 \\
\hline
\end{tabular}




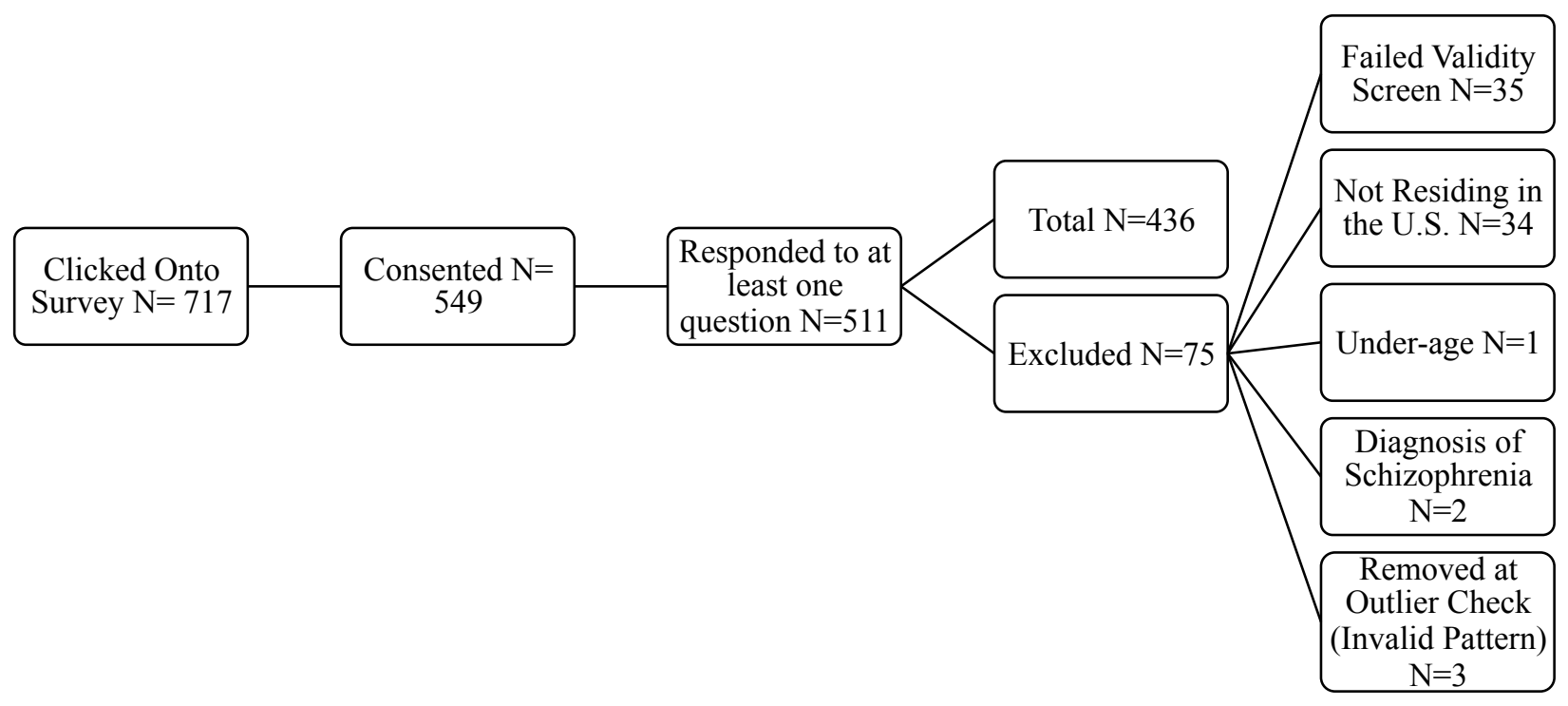

Figure 1. Diagram of recruitment. 


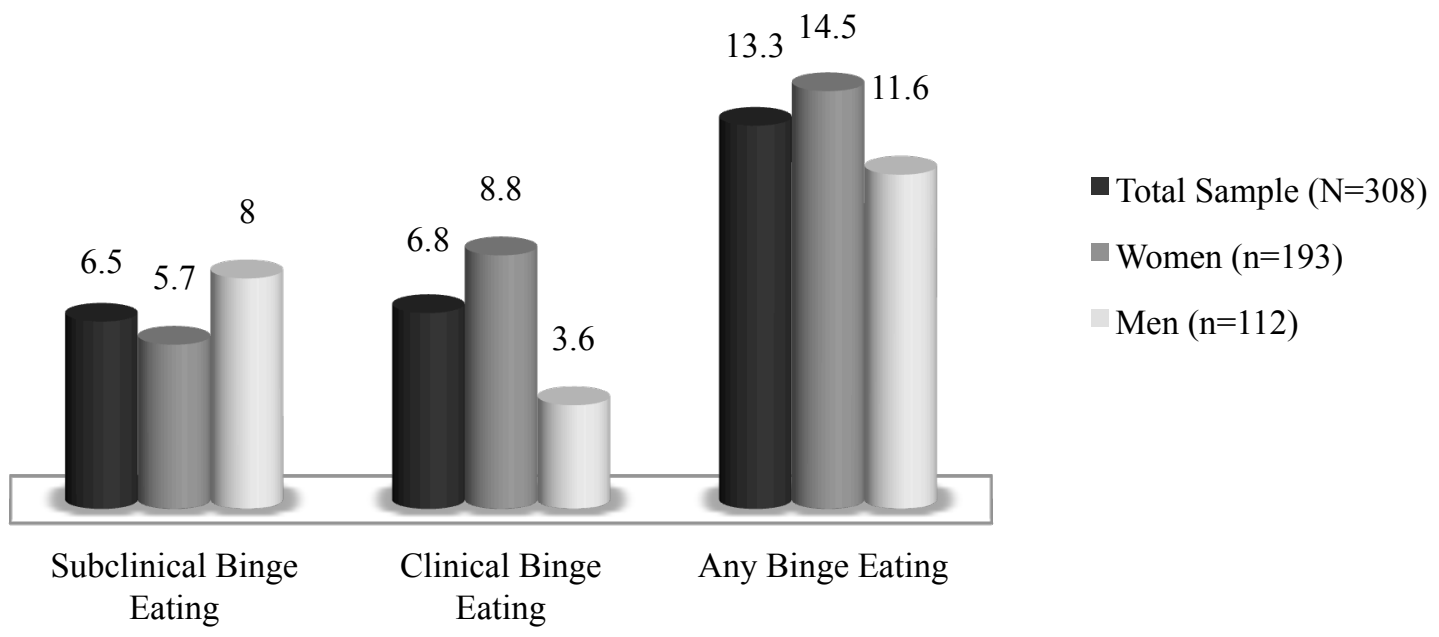

Figure 2. Binge eating prevalence by percent for total sample, women, and men. 


\section{Appendix A: Measures}

\begin{tabular}{|c|c|c|c|c|c|}
\hline \multirow{2}{*}{\multicolumn{2}{|c|}{$\begin{array}{l}\text { DASS21 } \\
\text { Please read each statement and circle a number } 0,1,2 \text { or } 3 \text { that indi } \\
\text { applied to you over the past month. There are no right or wrong answer } \\
\text { on any statement. } \\
\text { The rating scale is as follows: } \\
0 \text { Did not apply to me at all } \\
1 \text { Applied to me to some degree, or some of the time } \\
2 \text { Applied to me to a considerable degree, or a good part of time } \\
3 \text { Applied to me very much, or most of the time }\end{array}$}} & \multirow[t]{2}{*}{$\begin{array}{l}\text { ates } \\
\text { Do }\end{array}$} & not & $\begin{array}{l}\text { muc } \\
\text { pen }\end{array}$ & $\begin{array}{l}\text { the statement } \\
\text { too much time }\end{array}$ \\
\hline & & & & & \\
\hline 1 & I found it hard to wind down & 0 & 1 & 2 & 3 \\
\hline 2 & I was aware of dryness of my mouth & 0 & 1 & 2 & 3 \\
\hline 3 & I couldn't seem to experience any positive feeling at all & 0 & 1 & 2 & 3 \\
\hline 4 & $\begin{array}{l}\text { I experienced breathing difficulty (e.g., excessively rapid } \\
\text { breathing, } \\
\text { breathlessness in the absence of physical exertion) }\end{array}$ & 0 & 1 & 2 & 3 \\
\hline 5 & I found it difficult to work up the initiative to do things & 0 & 1 & 2 & 3 \\
\hline 6 & I tended to over-react to situations & 0 & 1 & 2 & 3 \\
\hline 7 & I experienced trembling (e.g., in the hands) & 0 & 1 & 2 & 3 \\
\hline 8 & I felt that I was using a lot of nervous energy & 0 & 1 & 2 & 3 \\
\hline 9 & $\begin{array}{l}\text { I was worried about situations in which I might panic and make } \\
\text { a fool of myself }\end{array}$ & 0 & 1 & 2 & 3 \\
\hline 10 & I felt that I had nothing to look forward to & 0 & 1 & 2 & 3 \\
\hline 11 & I found myself getting agitated & 0 & 1 & 2 & 3 \\
\hline 12 & I found it difficult to relax & 0 & 1 & 2 & 3 \\
\hline 13 & I felt down-hearted and blue & 0 & 1 & 2 & 3 \\
\hline 14 & $\begin{array}{l}\text { I was intolerant of anything that kept me from getting on with } \\
\text { what I was doing }\end{array}$ & 0 & 1 & 2 & 3 \\
\hline 15 & I felt I was close to panic & 0 & 1 & 2 & 3 \\
\hline 16 & I was unable to become enthusiastic about anything & 0 & 1 & 2 & 3 \\
\hline 17 & I felt I wasn't worth much as a person & 0 & 1 & 2 & 3 \\
\hline 18 & I felt that I was rather touchy & 0 & 1 & 2 & 3 \\
\hline 19 & $\begin{array}{l}\text { I was aware of the action of my heart in the absence of physical } \\
\text { exertion (e.g., sense of heart rate increase, heart missing a beat) }\end{array}$ & 0 & 1 & 2 & 3 \\
\hline 20 & I felt scared without any good reason & 0 & 1 & 2 & 3 \\
\hline 21 & I felt that life was meaningless & 0 & 1 & 2 & 3 \\
\hline
\end{tabular}




\section{$\underline{\text { Perceived Stress Scale }}$}

The questions in this scale ask you about your feelings and thoughts during the last month. In each case, you will be asked to indicate by circling how often you felt or thought a certain way.

$0=$ Never $1=$ Almost Never 2 = Sometimes 3 = Fairly Often $4=$ Very Often

1. In the last month, how often have you been upset because of something that happened unexpectedly?

2. In the last month, how often have you felt that you were unable to control the important things in your life? $\begin{array}{lllll}0 & 1 & 2 & 3 & 4\end{array}$

3. In the last month, how often have you felt nervous and "stressed"? $\begin{array}{lllll}.0 & 1 & 2 & 3 & 4\end{array}$

4. In the last month, how often have you felt confident about your ability to handle your personal problems?

5. In the last month, how often have you felt that things were going your way?.

6. In the last month, how often have you found that you could not cope with all the things that you had to do?

7. In the last month, how often have you been able to control irritations in your life?.

8. In the last month, how often have you felt that you were on top of things?...0 122234

9. In the last month, how often have you been angered because of things that were outside of your control?

10. In the last month, how often have you felt difficulties were piling up so high that you could not overcome them? 


\section{Eating Disorder Diagnostic Scale}

Please carefully complete all questions.

\begin{tabular}{|c|c|c|c|c|c|c|}
\hline Over the past 3 months... & & Slightly & & ately & & \\
\hline 1. Have you felt fat?. & 1 & 2 & 3 & 4 & 5 & 6 \\
\hline $\begin{array}{l}\text { 2. Have you had a definite fear that you } \\
\text { might gain weight or become fat?....... }\end{array}$ & 1 & 2 & 3 & 4 & 5 & 6 \\
\hline $\begin{array}{l}\text { 3. Has your weight influenced how you think } \\
\text { about (judge) yourself as a person?. . . . . . . }\end{array}$ & 1 & 2 & 3 & 4 & 5 & 6 \\
\hline $\begin{array}{l}\text { 4. Has your shape influenced how you think } \\
\text { about (judge) yourself as a person?. . . . . . }\end{array}$ & 1 & 2 & 3 & 4 & 5 & 6 \\
\hline
\end{tabular}

5. During the past 6 months have there been times when you felt you have eaten what other people would regard as an unusually large amount of food (e.g., a quart of ice cream) given the circumstances? YES NO

6. During the times when you ate an unusually large amount of food, did you experience a loss of control (feel you couldn't stop eating or control what or how much you were eating)? ......YES

7. How many DAYS per week on average over the past 6 MONTHS have you eaten an unusually large amount of food and experienced a loss of control? $\quad \begin{array}{llllllll}0 & 1 & 2 & 3 & 4 & 5 & 6 & 7\end{array}$

8. How many TIMES per week on average over the past 3 MONTHS have you eaten an unusually large amount of food and experienced a loss of control?

$\begin{array}{lllllllllllllll}0 & 1 & 2 & 3 & 4 & 5 & 6 & 7 & 8 & 9 & 10 & 11 & 12 & 13 & 14\end{array}$

\section{During these episodes of overeating and loss of control did you...}

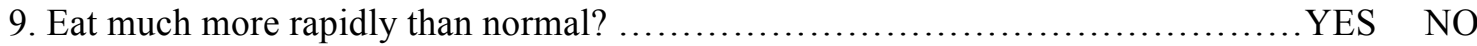

10. Eat until you felt uncomfortably full? ................................. YES NO

11. Eat large amounts of food when you didn't feel physically hungry? ............ YES NO

12. Eat alone because you were embarrassed by how much you were eating? ........ YES NO

13. Feel disgusted with yourself, depressed, or very guilty after overeating? ........ YES NO

14. Feel very upset about your uncontrollable overeating or resulting weight gain? ...YES NO 
15. How many times per week on average over the past $\mathbf{3}$ months have you made yourself vomit to prevent weight gain or counteract the effects of eating?

$\begin{array}{lllllllllllllll}0 & 1 & 2 & 3 & 4 & 5 & 6 & 7 & 8 & 9 & 10 & 11 & 12 & 13 & 14\end{array}$

16. How many times per week on average over the past $\mathbf{3}$ months have you used laxatives or diuretics to prevent weight gain or counteract the effects of eating?

$\begin{array}{lllllllllllllll}0 & 1 & 2 & 3 & 4 & 5 & 6 & 7 & 8 & 9 & 10 & 11 & 12 & 13 & 14\end{array}$

17. How many times per week on average over the past $\mathbf{3}$ months have you fasted (skipped at least 2 meals in a row) to prevent weight gain or counteract the effects of eating?

$\begin{array}{lllllllllllllll}0 & 1 & 2 & 3 & 4 & 5 & 6 & 7 & 8 & 9 & 10 & 11 & 12 & 13 & 14\end{array}$

18. How many times per week on average over the past $\mathbf{3}$ months have you engaged in excessive exercise specifically to counteract the effects of overeating episodes?

$\begin{array}{lllllllllllllll}0 & 1 & 2 & 3 & 4 & 5 & 6 & 7 & 8 & 9 & 10 & 11 & 12 & 13 & 14\end{array}$

19. How much do you weigh? If uncertain, please give your best estimate. lbs.

20. How tall are you? Please specify in inches $(5 \mathrm{ft} .=60 \mathrm{in}$. in.

21. Over the past 3 months, how many menstrual periods have you missed? $\quad \begin{array}{llllll}0 & 1 & 2 & 3 & \text { n/a }\end{array}$

22. Have you been taking birth control pills during the past 3 months? YES NO 


\section{Positive and Negative Affect Scale, Expanded Version (PANAS-X)}

This scale consists of a number of words and phrases that describe different feelings and emotions. Read each item and then mark the appropriate answer in the space next to that word. Indicate $t o$ what extent you have felt this way during the past month.

Use the following scale to record your answers:

$$
1
$$

very slightly

or not at all

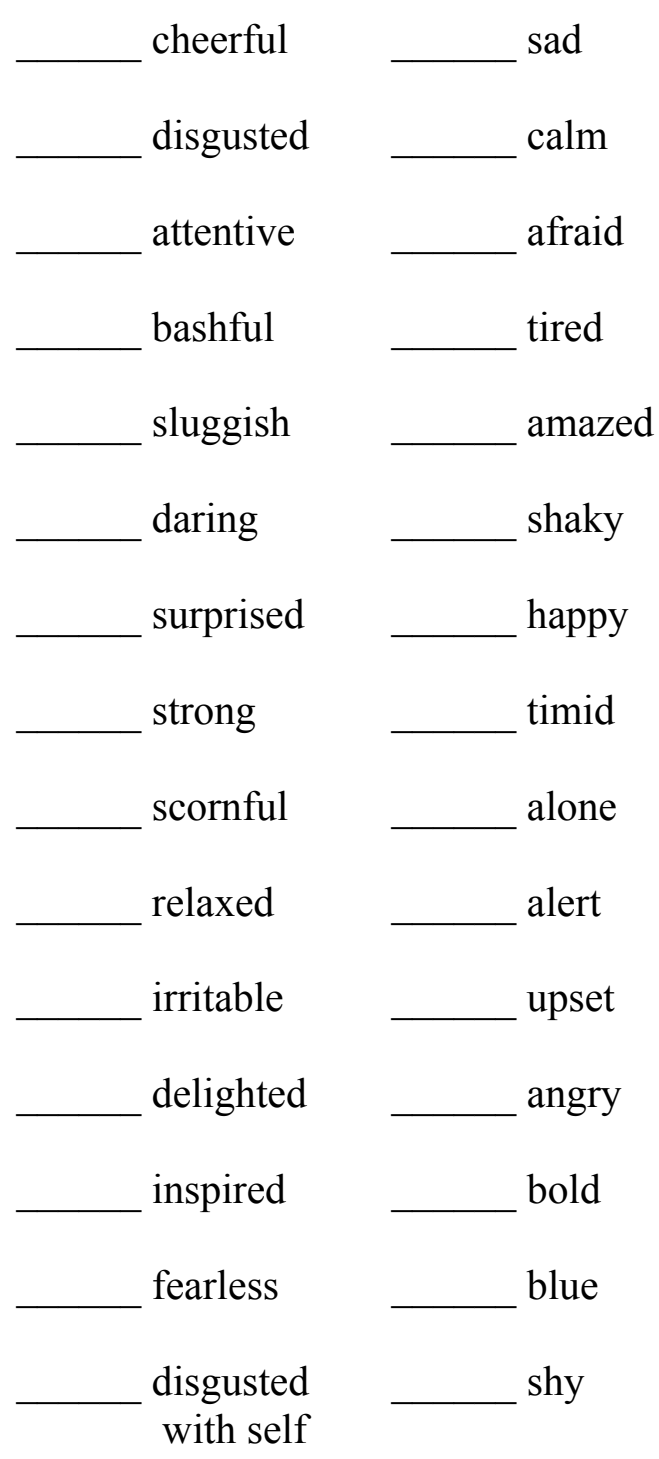

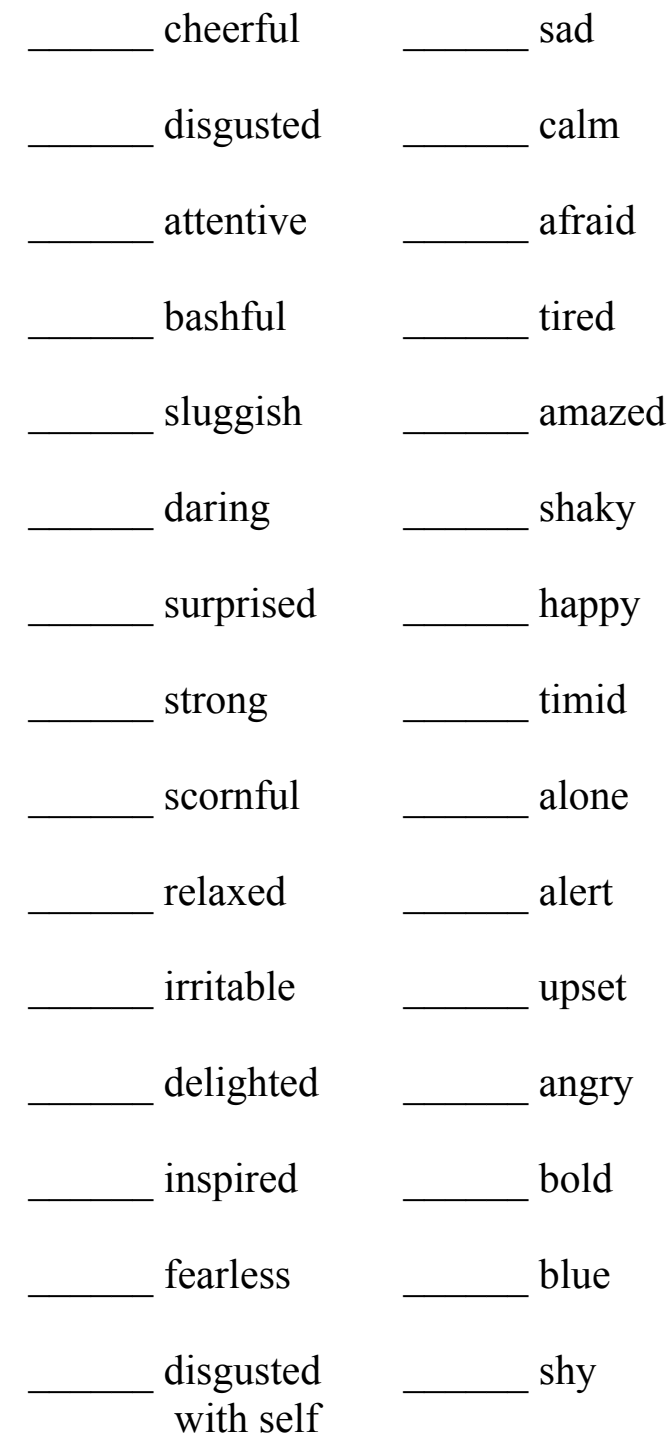

3

moderately
4

quite a bit
5

extremely

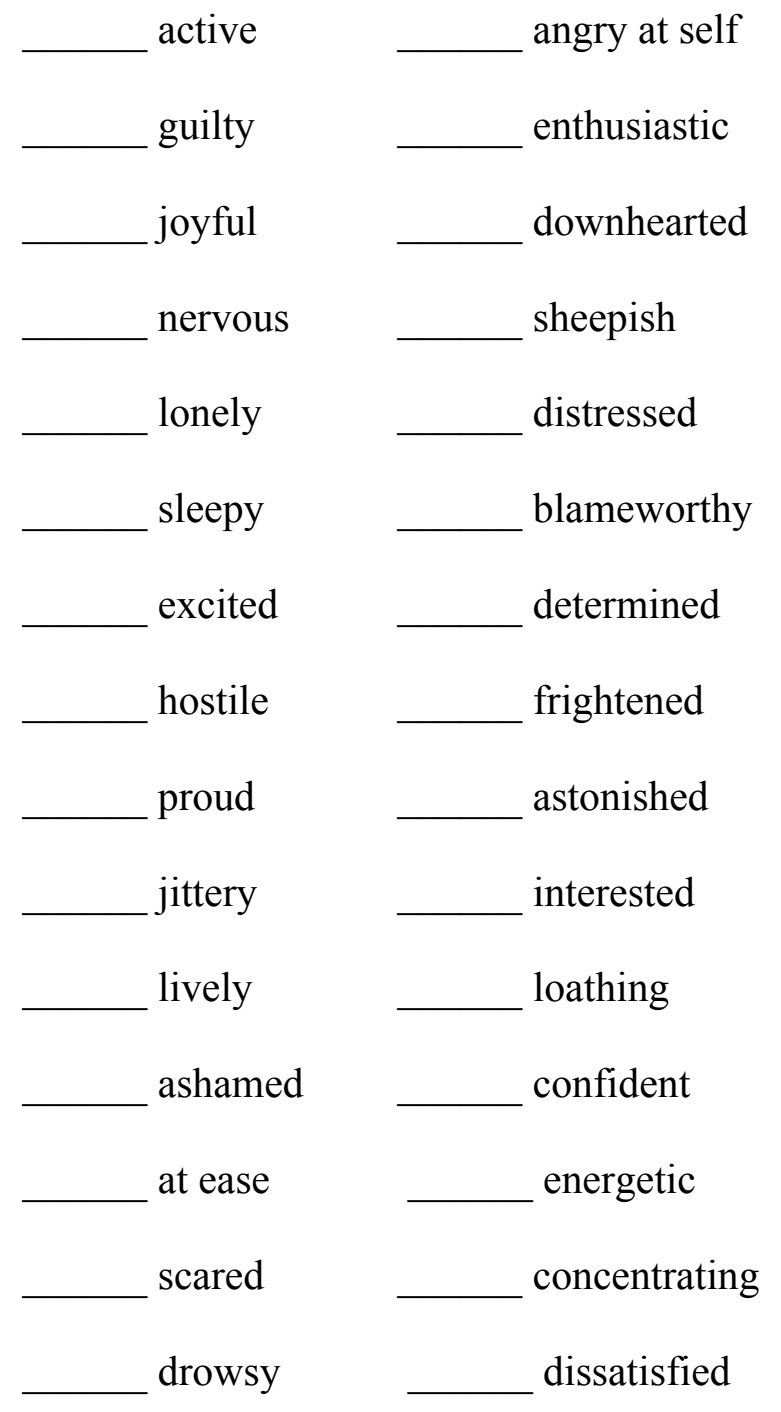




\section{WBSI}

This survey is about thoughts. There are no right or wrong answers, so please respond honestly to each of the items below. Be sure to answer every item by circling the appropriate letter beside each.

\begin{tabular}{|c|c|c|c|c|}
\hline A & B & $\mathrm{C}$ & D & $\mathrm{E}$ \\
\hline $\begin{array}{l}\text { Strongly } \\
\text { Disagree }\end{array}$ & Disagree & $\begin{array}{c}\text { Neutral or Don't } \\
\text { Know }\end{array}$ & Agree & $\begin{array}{c}\text { Strongly } \\
\text { Agree }\end{array}$ \\
\hline
\end{tabular}

A B C D E 1. There are things I prefer not to think about.

A B C D E 2. Sometimes I wonder why I have the thoughts I do.

A B C D E 3. I have thoughts that I cannot stop.

A B C D E 4. There are images that come to mind that I cannot erase.

A B C D E 5. My thoughts frequently return to one idea.

A B C D E 6. I wish I could stop thinking of certain things.

A B C D E 7. Sometimes my mind races so fast I wish I could stop it.

A B C D E 8. I always try to put problems out of mind.

A B C D E 9. There are thoughts that keep jumping into my head.

A B C D E 10. There are things that I try not to think about.

A B C D E 11. Sometimes I really wish I could stop thinking.

A B C D E 12. I often do things to distract myself from my thoughts.

A B C D E 13. I have thoughts that I try to avoid.

A B C D E 14. There are many thoughts that I have that I don't tell anyone.

A B C D E 15. Sometimes I stay busy just to keep thoughts from intruding on my mind. 